\title{
AN IMPERFECT PRODUCTION INVENTORY MODEL WITH ADVANCE PAYMENT AND CREDIT PERIOD IN A TWO-ECHELON SUPPLY CHAIN MANAGEMENT
}

\author{
Barun Khara ${ }^{1}$, Shyamal Kumar Mondal ${ }^{1}$ and Jayanta Kumar Dey ${ }^{2, *}$
}

\begin{abstract}
This paper presents an integrated imperfect production inventory model under two layer supply chain management. To ensure the orders, manufacturer convinces the retailer to pay a percentage of the purchasing cost prior to replenish the products and offers the facilities such as (i) delay in payment on the remaining part of the purchasing cost and (ii) free transportation on the basis of advance payment amount. Time dependent development cost is incurred to maintain the reliability of the production system and as a result it reduces the imperfectness of the product during production. Under such circumstances, an integrated profit function has been developed to find the optimum number of production cycle, optimum number of replenishment cycle and hence reliability parameter of the manufacturing system, replenishment quantity for the retailer which maximize the integrated profit. Branch and Bound technique is used to obtain the integer solutions. Furthermore, we derived some useful lemmas and algorithms to obtain the optimum solution. Finally, the model has been illustrated with some numerical examples exploring the sensitivity analysis with respect to some parameters and obtains some managerial insights.
\end{abstract}

Mathematics Subject Classification. 90B05, 90B30, 90B25, 90B50.

Received November 3, 2018. Accepted November 26, 2020.

\section{INTRODUCTION}

In present's competitive situation, supply chain management (SCM) plays a vital role in economy because it makes an integrated networking system among supplier, manufacturer, retailer and customer and learns how to survive in the present's competitive market through the co-operation among supplier, manufacturer, retailer and customer. It also co-ordinates a system of inter-related business process in order to procurement of raw materials, transportation of raw-materials, production of items, transportation of the finished product to the retailer for sale to satisfy their customers' demand. Along this direction, some previous research works to build an integrated SCM dates back to Bookbinder, Cachon and Zipkin [5], Agarwal et al. [1] and others. They have presented a production, distribution and inventory (PDI) planning system that integrated three supply

Keywords. Imperfect production, advance payment, replenishment cycle time, system reliability, credit period, branch and bound technique.

1 Department of Applied Mathematics with Oceanology and Computer Programming, Vidyasagar University, Midnapore 721102, West Bengal, India.

2 Mahishadal Raj College, Purba Medinipur, West Bengal, India.

${ }^{*}$ Corresponding author: dey_jaykum@yahoo.com 
chain segments comprised of supply, storage/location and customer demand planning. More works already have been developed on the integrated Economic Order Quantity (EOQ) model or Economic Production Quantity (EPQ) models on SCM by some researchers such as Manna et al. [29], Banerjee [2], Goyal [15], Sana [34], Das et al. $[7,8]$, De and Sana [13], De and Mahata $[9,10]$. To establish long term cooperation co-operation among supplier, manufacturer, retailer and customer it is very important to take initiative to developed supply chain model.

Generally, it has been observed that, in presence of several brands of the same product in the market, there is a fluctuation of demand rate and occurs error in demand. So to reduce the error in demand, that is, to ensure demand several distributors/manufacturers offer several types of facilities to stimulate their retailers and customers. In this regards so many research papers have been published. Thangam [41] presented optimal priced is counting and lot-sizing policies for perishable items in a supply chain under advance payment scheme and two-echelon trade credits. Taleizadeh et al. [39] considered an economic order quantity model with multiple partial prepayments and partial backordering. Zhang et al. [43] developed an optimal ordering policy in a twostage supply chain with advance payment for stable supply capacity. Ma et al. [27] presented an advance booking discount in the presence of spot market. Latter, more works in connection with advance payment have been discussed by Tavakoli and Taleizadeh [40], Lashgari et al. [24], Khan et al. [17], Shaikh et al. [35] etc. and several types of offers such as price discount etc. are announced. In connection with the SCM, transportation of finished product is one of the important factor. In so many existing literatures, due to advance payment by the retailers, the manufacturers allowed several kinds of offer such as partial credit period, price discount etc. but there does not exist no research work where the transportation offer is allowed due to advance payment.

Again, it has been observed that when a production system runs through long duration, several kinds of problem like labor, machinery, technology etc. arise and consequently, the manufacturing system produces both perfect and imperfect quality items. Perfect quality items are always ready for sale in exact price but imperfect items are either sold at reduced price or can be reworked to become new one. In this connection some works on imperfect productions have been discussed by Rosenblatt and Lee [32], Ben-Daya and Hariga [4], Maity et al. [28], Khara et al. [19]. Khouja and Mehrez [22] presented an economic production lot size model with imperfect quality and variable production rate. Salameh and Jaber [33] considered an inventory model which accounted for imperfect quality items using the EPQ/EOQ formula. Manna et al. [30] presented multi-item EPQ model with learning effect on imperfect production over fuzzy-random planning horizon. Also Manna et al. [31] developed an imperfect production inventory model with production rate dependent defective rate and advertisement dependent demand. Recently, De and Mahata [11] presented a cloudy fuzzy economic order quantity model for imperfect-quality items with allowable proportionate discounts. Khara et al. [20] developed a closed loop supply chain production model in an imperfect production system with acceptance quality level dependent development cost and demand. So, an important initiative can be taken to reduce the defective in a production house.

In economic order quantity (EOQ) model, it has been seen that the retailer pays the purchasing cost as soon as the products are delivered. To motivate the retailers, the manufacturers frequently offers the retailer a credit period, to pay the purchasing cost, which is a very usual. Furthermore, during the credit period, the retailer earns an interest by selling products and hence the retailers enjoy the financing benefit. In this regards, Goyal [14] at first presented an EOQ model with a constant demand rate under the condition of permissible delay in payments. Liang and Zhou [26] developed a two-warehouse inventory model for deteriorating items under conditionally permissible delay in payment. Some other works along the direction of credit period are Das et al. [6], Banu and Mondal [3], Khara et al. [21]. A comparison table of existing literatures with the proposed model is presented briefly in Table 1.

By summarizing the above discussion, the main contribution of this study are:

- To confirm the order, the manufacturer asks the retailer to pay a certain part of the purchasing cost of the replenishment quantity prior to replenish the products and invites to enjoy facilities (i) delay in payment on the remaining part of the replenishment quantity and (ii) free transportation on advance payment quantity subject to minimum order quantity determined by the manufacturer. 
TABLE 1. Summary of related literature about contributions of different authors.

\begin{tabular}{|c|c|c|c|c|c|c|}
\hline Author (s) & $\begin{array}{l}\mathrm{EOQ} / \\
\mathrm{EPQ}\end{array}$ & $\begin{array}{l}\text { Imperfect } \\
\text { production }\end{array}$ & $\begin{array}{l}\text { Customer's } \\
\text { demand }\end{array}$ & $\begin{array}{l}\text { Payment } \\
\text { advance } \\
\text { / delay }\end{array}$ & $\begin{array}{l}\text { Development } \\
\text { cost } \\
\text { depends on }\end{array}$ & $\begin{array}{l}\text { Offers due } \\
\text { to advance } \\
\text { payment }\end{array}$ \\
\hline $\begin{array}{l}\text { Gupta et al. } \\
{[16]}\end{array}$ & EOQ & NA & Constant & Partial advance & NA & Price discount \\
\hline $\begin{array}{l}\text { Zhang et al. } \\
{[42]}\end{array}$ & EOQ & NA & Constant & $\begin{array}{l}\text { Partial advance and } \\
\text { partial delay }\end{array}$ & NA & Price discount \\
\hline Thangam [41] & EOQ & NA & Constant & $\begin{array}{l}\text { Partial advance and } \\
\text { partial delay }\end{array}$ & NA & Price discount \\
\hline $\begin{array}{l}\text { Taleizadeh } \\
\text { et al. } \\
{[39]}\end{array}$ & EOQ & NA & Constant & Advance payment & NA & No \\
\hline $\begin{array}{l}\text { Taleizadeh } \\
\text { [37] }\end{array}$ & EOQ & NA & Constant & Partial advance & NA & No \\
\hline $\begin{array}{l}\text { Zia and } \\
\text { Taleizadeh [44] }\end{array}$ & EOQ & NA & Constant & $\begin{array}{l}\text { Partial advance and } \\
\text { partial delay }\end{array}$ & NA & No \\
\hline $\begin{array}{l}\text { Taleizadeh } \\
{[38]}\end{array}$ & EOQ & NA & Constant & Partial advance & NA & No \\
\hline $\begin{array}{l}\text { Lashgari et al. } \\
\text { [23] }\end{array}$ & EOQ & NA & Constant & $\begin{array}{l}\text { Partial advance and } \\
\text { partial delay }\end{array}$ & NA & No \\
\hline $\begin{array}{l}\text { Tavakoli and } \\
\text { Taleizadeh [40] }\end{array}$ & EOQ & NA & Constant & Partial advance & NA & No \\
\hline $\begin{array}{l}\text { Li et al. } \\
{[25]}\end{array}$ & EOQ & NA & $\begin{array}{l}\text { Selling price and } \\
\text { expiration date }\end{array}$ & $\begin{array}{l}\text { Partial advance and } \\
\text { partial delay }\end{array}$ & NA & No \\
\hline $\begin{array}{l}\text { Lashgari et al. } \\
\text { [24] }\end{array}$ & EOQ & NA & Constant & $\begin{array}{l}\text { Partial advance and } \\
\text { partial delay }\end{array}$ & NA & No \\
\hline $\begin{array}{l}\text { Shi et al. } \\
{[36]}\end{array}$ & EOQ & NA & Constant & $\begin{array}{l}\text { Partial advance and } \\
\text { partial delay }\end{array}$ & NA & Price discount \\
\hline $\begin{array}{l}\text { Khan et al. } \\
{[17]}\end{array}$ & EOQ & NA & $\begin{array}{l}\text { Price and } \\
\text { stock dependent }\end{array}$ & $\begin{array}{l}\text { Advance payment } \\
\text { full or partial }\end{array}$ & NA & Price discount \\
\hline $\begin{array}{l}\text { Khan et al. } \\
{[18]}\end{array}$ & EOQ & NA & $\begin{array}{l}\text { Price and } \\
\text { stock dependent }\end{array}$ & $\begin{array}{l}\text { Advance payment equal } \\
\text { installment } n \text { times }\end{array}$ & NA & Price discount \\
\hline $\begin{array}{l}\text { Shaikh et al. } \\
\text { [35] }\end{array}$ & EOQ & NA & $\begin{array}{l}\text { Price } \\
\text { dependent }\end{array}$ & Advance payment & NA & No \\
\hline $\begin{array}{l}\text { Present } \\
\text { paper }\end{array}$ & EPQ & Yes & Constant & $\begin{array}{l}\text { Partial advance and } \\
\text { partial delay }\end{array}$ & $\begin{array}{l}\text { Time and } \\
\text { reliability } \\
\text { parameter }\end{array}$ & $\begin{array}{l}\text { free } \\
\text { Transportation }\end{array}$ \\
\hline
\end{tabular}

Notes. NA means that the contribution is Not Available for that research.

- To reduce the imperfectness of the production system (i.e., to maintain the reliability of the production system), a time dependent development cost has been incorporated.

- In supply chain management, co-ordination is most important among the chain members and the retailers play a vital role as they directly handle to the end customers. In this regards, manufacturer gives different types of facilities to the retailers such as trade credits, price discount etc. Here we assume that if the retailer cannot sale the items within the credit period then interest charged by the manufacturer for the rest amount is same as the interest earned from the bank deposits whereas in the existing literatures, the charged amount is much more from the bank interest.

Incorporating the above mentioned phenomenon, we have considered a two layer supply chain production inventory model with imperfect product with constant demand rate under permissible delay in payments depending on a part of the advance payment. In addition, the manufacturer charges an interest from the retailer on the remaining non selling stock after the credit period which inspires the retailer. Under these circumstances, 
an integrated profit function has been made to find (i) optimum number of production cycle (ii) optimum number of replenishment cycle (iii) optimum value of the reliability parameter of the production system (iv) optimum replenishment cycle time and (v) optimum replenishment quantity to achieve maximum integrated profit. Numerical examples incorporating with several managerial insights are also presented.

The paper is arranged as: In Section 2, assumptions and notations of the model are displayed. In Section 3, the proposed model is formulated and presented. In Section 4, solution methodology. In Section 5, the numerical illustration with sensitivity analysis and managerial insight in favor of the model has been given. Finally, the paper is concluded including the future research in Section 8.

\section{Assumption AND NOTATION}

To develop the proposed integrated imperfect production inventory model with two layer supply chain, the following notations and assumptions have been used.

\subsection{Notations}

$q_{m p}(t)$ : On hand inventory of perfect items for manufacturer at time $t \geq 0$

$q_{m d}(t)$ : On hand inventory of imperfect items for manufacturer at time $t \geq 0$.

$q_{r}(t)$ : On hand inventory of perfect items for retailer at time $t \geq 0$.

$T$ : Replenishment cycle time.

$n$ : Number of replenishment cycle (decision variable).

$r$ : Number of production cycle (decision variable) where $r \leq n$.

$n T$ : Business period.

$r T$ : Production time.

$Q$ : Replenishment quantity for each cycle of length $T$.

$Q_{0}$ : Minimum quantity to replenish.

$\alpha Q$ : Advance payment quantity for each cycle of length $T$ (where $0 \leq \alpha<1$ ).

$D_{c}$ : Constant demand rate of customer.

$p$ : Constant production rate for manufacturer.

$A_{r}$ : Ordering cost for retailer.

$s_{m p}$ : Selling price of per unit perfect item from manufacturer to retailer.

$s_{m d}$ : Selling price per unit defective item for manufacturer to retailer.

$s_{r}$ : Selling price of per unit perfect item from retailer to customer.

$M$ : Credit period offered by the manufacturer.

$i_{d r}$ : Interest rate on the deposited amount by the retailer to the Bank.

$i_{m p}$ : Interest rate for opportunity loss due to the credit period offered by the manufacturer.

$i_{c m}$ : Interest rate charged by the manufacturer to retailer from the remaining stock from the time period $M$ to $T$.

$c_{h r}$ : Holding cost per unit item per unit time for retailer.

$c_{h m}$ : Holding cost per unit item per unit time for manufacturer.

$c_{s m}$ : Screening cost per unit item for manufacturer.

$c_{t r}$ : Transportation cost per unit item charged by the manufacturer from retailer.

$c_{t u}$ : Manufacturer's transportation cost for the replenishment quantity $Q_{0}$.

$\theta$ : Reliability parameter of the manufacturing system (dependent decision variable) which belongs in $\left[\theta_{\min }, \theta_{\max }\right]$.

$V(\theta, t)$ : Development cost at production time $t$ for $\theta$.

$A$ : The fixed cost like labor cost and energy cost which is independent of the reliability parameter $(\theta)$.

$B$ : The cost of technology, resource and design complexity for production when $\theta=\theta_{\max }$ and $t=(\tau+1)$.

$k$ : The difficulties in increasing reliability of the manufacturing system. 
$C(\theta, t)$ : Unit production cost of the item.

$\delta$ : Variation constant of tool/die costs.

APR: Average profit for retailer.

APM: Average profit for manufacturer.

AIP: Average integrated profit.

\subsection{Assumptions}

(i) The model is developed for a single item with single manufacturer and single retailer.

(ii) Joint effect of manufacturer and retailer has been considered.

(iii) The manufacturer produces at a constant rate of production $p$ units per unit time to satisfy customer's constant demand $D_{c}$ units per unit time.

(iv) Since, the production system produces a mixture of perfect and imperfect items due to the various factors involved in the production system, here screening process has been considered to identify whether a produced item is perfect or imperfect. Therefore, as soon as the production is started, the screening process is also started at the screening cost $c_{s m}$ per unit item and it is continued upto the end of the production.

(v) In connection with the advance payment, the manufacturer strategically establishes a policy "more advance payment prior to less time of replenishment but less advance payment prior to more time of replenishment". In this paper, it has been assumed that the manufacturer asks the retailer to pay $\alpha$ part of the replenishment quantity $Q$ in advance prior to $(1-\alpha) T$ time of replenishment and says to enjoy free transportation on $\alpha Q$ quantity as well as credit period $M=\alpha T$ on the remaining $(1-\alpha) Q$ quantity (see Fig. 1).

(vi) Manufacturer allows the opportunity to the retailer permissible delay in payment $M$.

(vii) The credit period $M$ offered by the manufacturer must be within the replenishment cycle $T$ i.e., $(0<$ $M \leq T)$.

(viii) The manufacturer charges an interest on the amount of the remaining stock at the rate of $i_{c m}$ after the credit period $M$.

(ix) Shortages are not allowed.

(x) The replenishment is considered instantaneously.

(xi) The reliability of the manufacturing system at time $t$ has been considered as $e^{-\theta t}$ where $\theta$ be the reliability parameter of the manufacturing system defined as

$$
\theta=\frac{\text { number of imperfect items }}{\text { total number of items produced within an operating hour }}
$$

which shows that reliability of the system increases as the value of $\theta$ decreases.

(xii) As $p$ is assumed as the production rate and $e^{-\theta t}$ is the reliability of the manufacturing system at any instant $t$ so $p e^{-\theta t}$ is the rate of producing perfect items at time $t$ and $p\left(1-e^{-\theta t}\right)$ is the rate of producing imperfect items at time $t$.

(xiii) In this two layers supply chain production inventory model, the retailer only receives perfect items from manufacturer to satisfy his/her customer's demand.

(xiv) Perfect quality items are ready for sale in exact price but imperfect items are sold with reduced price in a single lot at the end of production as a whole.

(xv) According to our assumption $(x i)$, it is clear that the reliability of production system decreases as time passes. So, it is needed to consider a development cost to maintain a fixed reliability of the production system during production process. Furthermore, to increase the reliability of the system, the development cost must be increased. Therefore, the development cost for production $V(\theta, t)$ must be a function of time $t$ and $\theta$ which has been considered as follows:

$$
V(\theta, t)=A+B t e^{k\left(\frac{\theta_{\max }-\theta}{\theta-\theta_{\min }}\right)}
$$




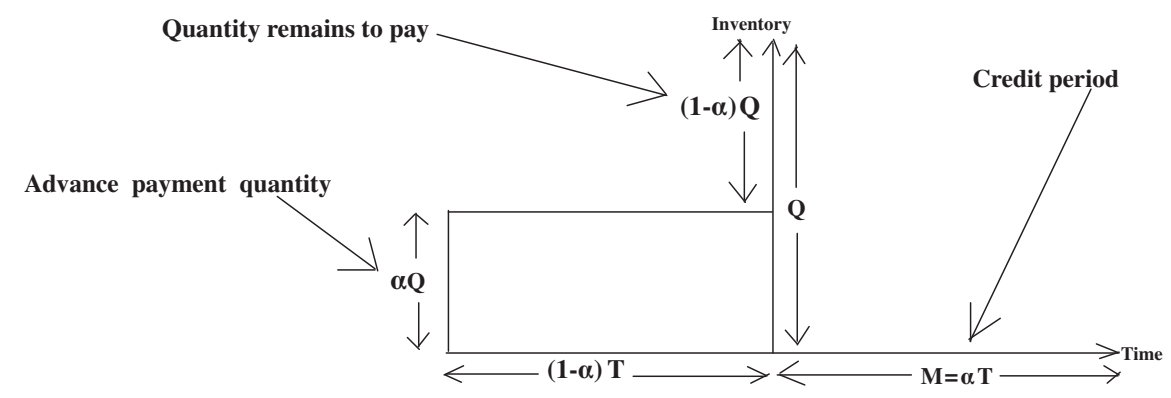

FIGURE 1. Schematic diagram of the partial advance and the partial delay payment of $Q$.

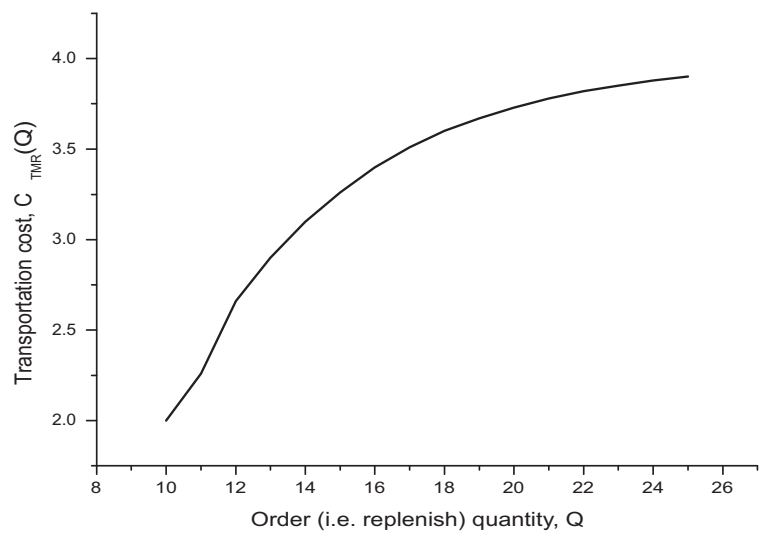

FIGURE 2. Graphical representation of transportation cost verses replenishment quantity.

where $A$ is a fixed cost like labor and energy which does not depend on $\theta$. B is the cost of technology, resource and design complexity for production when $\theta=\theta_{\max }$ and $t=1$.

(xvi) To motivate the retailer, the manufacturer offers (a) $\alpha$ part of the replenishment quantity $Q$ to transport as free as well as (b) a credit period $M=\alpha T$ on the remaining replenish quantity $(1-\alpha) Q$ subject to the condition that the retailer must have (i) to replenish (order) a minimum $Q_{0}$ quantity and (ii) to prepay $\alpha$ part of the replenishment quantity $Q$ prior to $(1-\alpha) T$ time of replenishment. In practice, it has been observed that the transportation cost per unit item decreases as transport quantity increases. For this reason, the transportation cost function $C_{\mathrm{TMR}}(Q)$ to transport $Q$ quantity has been considered as an increasing function of the replenishment quantity $Q$ but increasing rate is decreased as like as Khara et al. [21] as given below.

$$
C_{\mathrm{TMR}}(Q)=c_{t u}\left\{2-e^{-\beta\left(Q-Q_{0}\right)}\right\}, Q>Q_{0}
$$

where $c_{t u}$ is the cost of transportation for $Q_{0}$ quantity. The graphical representation of the transportation cost function $C_{\mathrm{TMR}}(Q)$ shown in Figure 2.

(xvii) Production survey reveals that the production cost depends not only on the material cost $m_{0}$, but also depends on the development cost $V(\theta, t)$ and tool/die cost. So, the production cost $C(\theta, t)$ per unit item must be a function of the following type:

$$
C(\theta, t)=m_{0}+\frac{V(\theta, t)}{p}+\delta p
$$


where $\delta$ be the proportional constant of tool or die cost which depends on the number of produced items $p$.

(xviii) To stimulate the retailer, manufacturer strategically offers the credit period $M$ within the replenishment cycle $T$ i.e., $(0<M \leq T)$ as given by

$$
M=\alpha T
$$

where $\alpha$ is the constant coefficient to increase the credit period.

(xix) In this model, business period $n T$ is fixed and is considered as one year (i.e., $n T=1$ ).

\section{MODEL FORMULATION}

In this two layer supply chain production inventory model, the manufacturer starts the production at time $t=0$ with constant rate of production $p$. In general, it has been observed that the manufacturing system produces a mixture of both perfect and imperfect items due to varieties of problem like labor, machinery, technology etc when it runs through long duration. Perfect items are ready for sale and the imperfect items are sold at reduced price at the end of the production in a single lot. These defective items can be reduced by improvement in technology with the application of the time dependent development cost $V(\theta, t)$. After the production time $T$ the retailer first receives only the perfect quality items $Q$ units from the manufacturer and with this stock the retailer satisfies its customer's demand $D_{c}$ throughout the replenishment cycle $T$. Again, the retailer receives the same quantity $Q$ units of perfect items after time $T$ from the manufacturer and this is repeated till $n$ cycle and at time $(n+1) T$ the retailer finishes the stock. The Figure 3 shows the characteristic of the integrated two layer supply chain production inventory model.

The governing differential equation of the inventory $q_{r}(t)$ for retailer is given by

$$
\frac{\mathrm{d} q_{r}(t)}{\mathrm{d} t}=-D_{c}, \quad 0 \leq t \leq T
$$

with boundary conditions $q_{r}(0)=Q$ and $q_{r}(T)=0$.

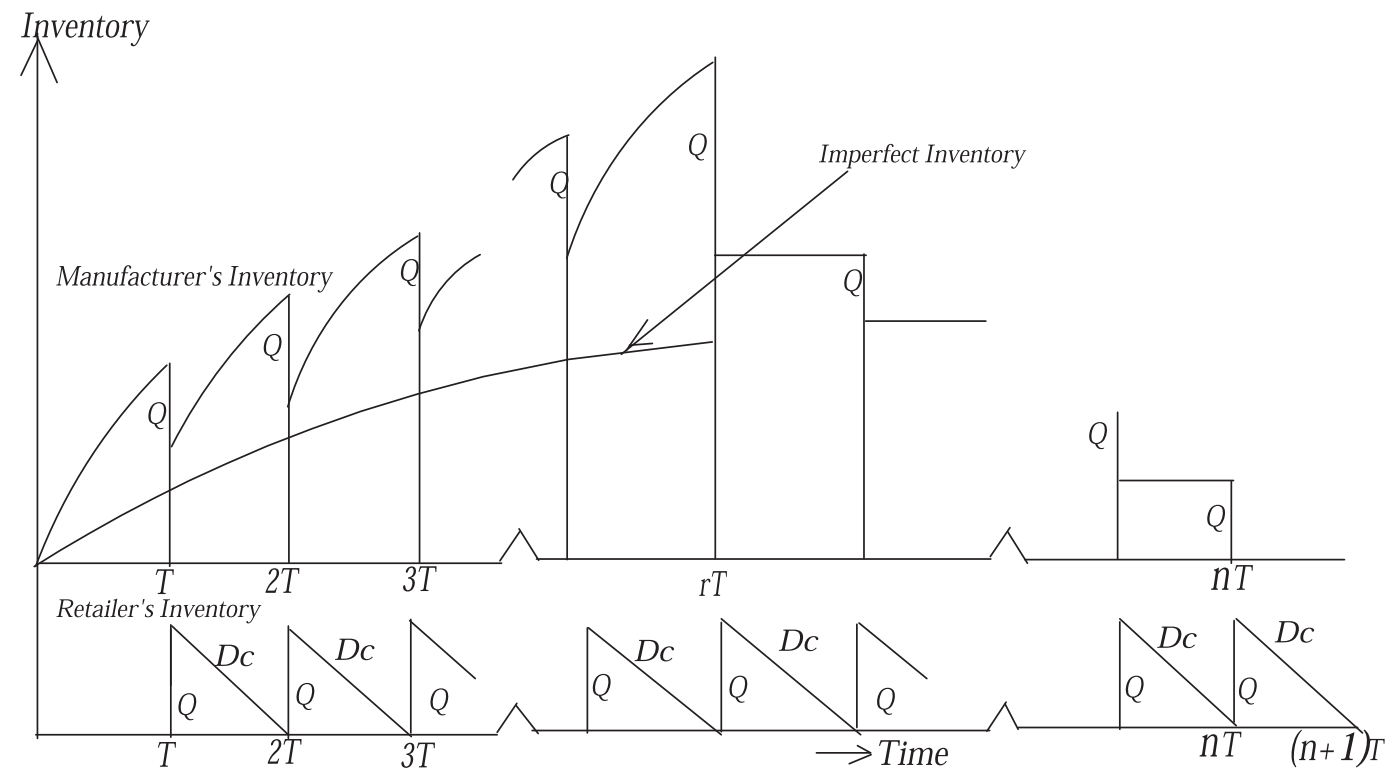

FiguRE 3. Logistic diagram of the inventory of the integrated production inventory model. 
Integrating the above differential equation using the boundary conditions, the inventory level $q_{r}(t)$ for retailer at any instant $t$ is as follows:

$$
q_{r}(t)=Q-D_{c} t, \quad 0 \leq t \leq T
$$

Lemma 3.1. The cycle time $T$, the replenishment quantity $Q$ and the customer's demand are connected as $Q=D_{c} T$.

Proof. As retailer's inventory becomes zero at $t=T$ according to our assumption, so $q_{r}(T)=0$ implies $Q-D_{c} T=0$ which gives $Q=D_{c} T$.

Average holding cost for retailer is given by

$$
\mathrm{RAHC}=\frac{c_{h r}}{T} \int_{0}^{T} q_{r}(t) \mathrm{d} t=\frac{c_{h r}}{T} \int_{0}^{T}\left(Q-D_{c} t\right) \mathrm{d} t=c_{h r}\left(Q-\frac{D_{c} T}{2}\right)=c_{h r} \frac{Q}{2} .
$$

Average ordering cost for retailer is given by

$$
\mathrm{RAOC}=\frac{A_{r}}{T}
$$

Retailer's average revenue from selling is

$$
\mathrm{RAREV}=\frac{s_{r} Q}{T} .
$$

Average interest earned from the Bank due to delay payment by the retailer is given by

$$
\mathrm{RAIE}=\frac{s_{r} i_{d r}}{T} \int_{0}^{M} D_{c}(M-t) \mathrm{d} t=\frac{s_{r} i_{d r}}{T} D_{c}\left(M^{2}-\frac{M^{2}}{2}\right)=\frac{1}{2 T} s_{r} i_{d r} D_{c} M^{2} .
$$

Manufacturer's average interest charged from retailer on the remaining stock after credit period given on the left quantity $(1-\alpha) Q$ after the advance payment quantity $\alpha Q$ is

$$
\begin{aligned}
\text { MAIC } & =\frac{s_{m p} i_{c m}}{T} \int_{M}^{T} q_{r}(t) \mathrm{d} t=\frac{s_{m p} i_{c m}}{T} \int_{M}^{T}\left\{(1-\alpha) Q-D_{c} t\right\} \mathrm{d} t \\
& =\frac{1}{T} s_{m p} i_{c m}(T-M)\left\{(1-\alpha) Q-\frac{1}{2} D_{c}(T+M)\right\} .
\end{aligned}
$$

Lemma 3.2. The advance payment part $\alpha$ of the replenishment quantity $Q$ lies between 0 and $\frac{1}{3}$ i.e., $0<\alpha \leq \frac{1}{3}$ is the feasible region for $\alpha$.

Proof. Manufacturer's average interest charged from retailer on the remaining stock after credit period given on the left quantity $(1-\alpha) Q$ after the advance payment quantity $\alpha Q$ is MAIC $=\frac{1}{T} s_{m p} i_{c m}(T-M)\{(1-\alpha) Q-$ $\left.\frac{1}{2} D_{c}(T+M)\right\}$ which implies

$$
\begin{array}{r}
\left\{(1-\alpha) Q-\frac{1}{2} D_{c}(T+M)\right\} \geq 0 \\
\text { i.e., }(1-\alpha) D_{c} T-\frac{1}{2}(T+\alpha T) D_{c} \geq 0
\end{array}
$$




$$
\text { i.e., } \begin{array}{r}
\frac{D_{c} T}{2}(2-2 \alpha-1-\alpha) \geq 0 \\
\text { i.e., } 3 \alpha \leq 1 \\
\text { i.e., } \alpha \leq \frac{1}{3} .
\end{array}
$$

Hence proved.

Retailer's average interest loss for advance payment amount $\alpha Q$ prior $(1-\alpha) T$ time to replenishment is

$$
\text { RAILAP }=\frac{1}{T} i_{d r} s_{m p} \alpha Q(1-\alpha) T .
$$

Average transportation cost on the remaining $(1-\alpha) Q$ quantity exempt from free transportation charged by the manufacturer from retailer is

$$
\mathrm{RATCM}=\frac{1}{T} c_{t r}(1-\alpha) Q
$$

Average purchasing cost for retailer is

$$
\mathrm{RAPC}=\frac{1}{T} s_{m p} Q
$$

Average profit for retailer (APR) is given by

$$
\begin{aligned}
\mathrm{APR}= & \mathrm{RAREV}+\mathrm{RAIE}-\mathrm{RAPC}-\mathrm{RAHC}-\mathrm{MAIC}-\mathrm{RAOC}-\mathrm{RAILAP}-\mathrm{RATCM} \\
= & \frac{1}{T}\left[\left(s_{r}-s_{m p}\right) Q+\frac{1}{2} s_{r} i_{d r} D_{c} M^{2}-c_{h r} T \frac{Q}{2}-s_{m p} i_{c m}(T-M)\left\{(1-\alpha) Q-\frac{1}{2} D_{c}(T+M)\right\}-A_{r}\right. \\
& \left.-i_{d r} s_{m p} \alpha Q(1-\alpha) T-c_{t r}(1-\alpha) Q\right] .
\end{aligned}
$$

According to the assumption, the manufacturer starts the production at $t=0$ and stops production at the end of $r$ cycles. As the production is continued till $r T$ time, the inventory level is increased up-to $r T$ time and the stock is decreased at the rate of $Q$ units per replenishment cycle time $T$ by the retailer and the stock is finished at the end of the time $n T$ when the retailer receives the last replenishment $Q$ units as presented in Figure 3.

The governing differential equation of the inventory $q_{m p}(t)$ for the manufacturer is given by

$$
\frac{\mathrm{d} q_{m p}(t)}{\mathrm{d} t}=p e^{-\theta t}, \quad 0 \leq t \leq T
$$

with initial condition $q_{m p}(0)=0$.

The inventory $q_{m p}(t)$ of perfect items for manufacturer as in Figure 3 is given by

$$
q_{m p}(t)=\left\{\begin{array}{ll}
\frac{p}{\theta}\left(1-e^{-\theta t}\right) & \text { if } 0 \leq t<T \\
\frac{p}{\theta}\left(1-e^{-\theta t}\right)-i Q & \text { if } i T \leq t<(i+1) T, i=1,2, \ldots,(r-1) \\
\frac{p}{\theta}\left(1-e^{-\theta r T}\right)-j Q & \text { if } j T \leq t<(j+1) T, j=r,(r+1),(r+2), \ldots, n
\end{array} .\right.
$$

Lemma 3.3. The system reliability parameter $\theta$, the replenishment quantity $Q$, the cycle time $T$, number of production cycle $r$ and number of replenishment cycle $n$ are connected by the equation $\frac{p}{\theta}\left(1-e^{-\theta r T}\right)=n Q$.

Proof. According to the assumption the manufacturer's inventory for perfect items becomes zero at $t=n T$, so $q_{m p}(n T)=0$ implies $\frac{p}{\theta}\left(1-e^{-\theta r T}\right)-n Q=0$ which gives $\frac{p}{\theta}\left(1-e^{-\theta r T}\right)=n Q$.

Lemma 3.4. The system reliability parameter $\theta$ is a function of the number of production cycle $r$ and the number of replenishment cycle $n$ connected by the equation $\theta=\frac{2 n^{2}}{p r^{2}}\left(\frac{p r}{n}-D_{c}\right)$. 
Proof. According to Lemma 3.3, we have $\frac{p}{\theta}\left(1-e^{-\theta r T}\right)=n Q=n D_{c} T=D_{c}$, as $n T=1$. As $r \leq n, 0<\theta<1$ and $n T=1, r T<1$ and so $\theta^{3} r^{3} T^{3} \ll 1$. Therefore, neglecting cube and higher order of $\theta r T$ we get as follows

$$
\begin{array}{r}
\frac{p}{\theta}\left\{1-\left(1-r T \theta+\frac{r^{2} T^{2} \theta^{2}}{2}-\frac{r^{3} T^{3} \theta^{3}}{6}+\ldots\right)\right\}=D_{c} \\
\text { i.e., } p r T-\frac{\theta p r^{2} T^{2}}{2}=D_{c} \\
\text { i.e., } \theta=\frac{2}{p r^{2} T^{2}}\left(p r T-D_{c}\right) \\
\text { i.e., } \theta=\frac{2 n^{2}}{p r^{2}}\left(\frac{p r}{n}-D_{c}\right) .
\end{array}
$$

Hence proved.

Holding cost of perfect items for manufacturer is given by

$$
\begin{aligned}
\mathrm{MHCP} & =c_{h m}\left[\int_{0}^{T} \frac{p}{\theta}\left(1-e^{-\theta t}\right) \mathrm{d} t+\sum_{1}^{r-1} \int_{i T}^{(i+1) T}\left\{\frac{p}{\theta}\left(1-e^{-\theta t}\right)-i Q\right\} \mathrm{d} t+\sum_{r}^{n} \int_{j T}^{(j+1) T}(n Q-j Q) \mathrm{d} t\right] \\
& =c_{h m}\left\{\frac{1}{\theta} r p T-\frac{1}{\theta} n Q+\frac{1}{2} Q T(n-r)(n-r+1)-\frac{1}{2} Q T r(r-1)\right\} \\
& =c_{h m}\left\{\frac{1}{\theta} r p T-\frac{1}{\theta} n Q+\frac{1}{2} Q T n(n-2 r+1)\right\} .
\end{aligned}
$$

Again, the differential equation of the inventory $q_{m d}(t)$ for the imperfect items for manufacturer is

$$
\frac{\mathrm{d} q_{m d}(t)}{\mathrm{d} t}=p\left(1-e^{-\theta t}\right), \quad 0 \leq t \leq r T
$$

with initial condition $q_{m d}(0)=0$.

After solving the above differential equation using the initial condition, the stock level $q_{m d}(t)$ for the imperfect items at any instant $t$ is

$$
q_{m d}(t)=p\left\{t-\frac{1}{\theta}\left(1-e^{-\theta t}\right)\right\}, \quad 0 \leq t \leq r T .
$$

The holding cost for imperfect items for the manufacturer is given by

$$
\begin{aligned}
\mathrm{MHCD} & =c_{h m} \int_{0}^{r T} q_{m d}(t) \mathrm{d} t=c_{h m} \int_{0}^{r T} p\left\{t-\frac{1}{\theta}\left(1-e^{-\theta t}\right)\right\} \mathrm{d} t \\
& =c_{h m} p\left(\frac{1}{2} r^{2} T^{2}-\frac{1}{\theta} r T+\frac{1}{p \theta} n Q\right) .
\end{aligned}
$$

Total production cost for manufacturer is as follows

$$
\begin{aligned}
\mathrm{MPC} & =p \int_{0}^{r T} C(\theta, t) \mathrm{d} t=p \int_{0}^{r T}\left\{m_{0}+\frac{V(\theta, t)}{p}+\delta p\right\} \mathrm{d} t \\
& =p \int_{0}^{r T} m_{0} \mathrm{~d} t+\int_{0}^{r T}\left\{A+B t e^{k\left(\frac{\theta_{\max }-\theta}{\theta-\theta_{\min }}\right)}\right\} \mathrm{d} t+\int_{0}^{r T} \delta p^{2} \mathrm{~d} t \\
& =\left\{p m_{0}+A+\delta p^{2}\right\} r T+\frac{B}{2} r^{2} T^{2} e^{k\left(\frac{\theta_{\max }-\theta}{\theta-\theta_{\min }}\right)} .
\end{aligned}
$$


The revenue from the sell of the perfect items for the manufacturer is obtained as

$$
\operatorname{MREVP}=s_{m p} \int_{0}^{r T} p e^{-\theta t} \mathrm{~d} t=\frac{1}{\theta} p s_{m p}\left(1-e^{-\theta r T}\right)=s_{m p} n Q
$$

The revenue from the sale of defective items for the manufacturer with reduced selling price $s_{m d}$ is given by

$$
\operatorname{MREVD}=s_{m d} \int_{0}^{r T} p\left(1-e^{-\theta t}\right) \mathrm{d} t=p s_{m d}\left\{r T-\frac{1}{\theta}\left(1-e^{-\theta r T}\right)\right\}=s_{m d}(p r T-n Q) .
$$

Manufacturer's opportunity loss for offering credit period is given by

$$
\text { MOLDP }=n i_{m p} s_{m p} M(1-\alpha) Q .
$$

The total screening cost for the manufacturer to identify the items whether it is perfect or imperfect is given by

$$
\operatorname{MSCRC}=c_{s m} \int_{0}^{r T} p \mathrm{~d} t=c_{s m} p r T .
$$

Interest charged by the manufacturer to the retailer after the credit period $M$ is

$$
\mathrm{MICR}=n s_{m p} i_{c m} \int_{M}^{T}\left\{(1-\alpha) Q-D_{c} t\right\} \mathrm{d} t=n s_{m p} i_{c m}(T-M)\left\{(1-\alpha) Q-\frac{1}{2} D_{c}(T+M)\right\} .
$$

Manufacturer's transportation cost is

$$
\mathrm{MTC}=n C_{\mathrm{TMR}}(Q)=n c_{t u}\left\{2-e^{-\beta\left(Q-Q_{0}\right)}\right\} .
$$

Manufacturer's revenue from retailer to transport the remaining $(1-\alpha) Q$ quantity exempt from free is

$$
\text { MREVTC }=n c_{t r}(1-\alpha) Q .
$$

Interest earned by the manufacturer due to $\alpha$ percent advance payment of the replenishment quantity $Q$ prior to $(1-\alpha) T$ time of replenishment is

$$
\mathrm{MIEAP}=n s_{m p} i_{e m} \alpha Q(1-\alpha) T .
$$

Average profit for the manufacturer (APM) is given by

$$
\begin{aligned}
\mathrm{APM}= & \frac{1}{n T}(\mathrm{MREVP}+\mathrm{MREVD}+\mathrm{MICR}+\mathrm{MIEAP}+\mathrm{MREVTC}-\mathrm{MPC} \\
& -\mathrm{MHCP}-\mathrm{MHCD}-\mathrm{MOLDP}-\mathrm{MSCRC}-\mathrm{MTC}) \\
= & \frac{1}{n T}\left[s_{m p} n Q+s_{m d}(p r T-n Q)+n s_{m p} i_{c m}(T-M)\left\{(1-\alpha) Q-\frac{1}{2} D_{c}(T+M)\right\}\right. \\
& +n s_{m p} i_{e m} \alpha Q(1-\alpha) T+n c_{t r}(1-\alpha) Q-\left\{p m_{0}+A+\delta p^{2}\right\} r T-\frac{B}{2} r^{2} T^{2} e^{k\left(\frac{\theta_{\max }-\theta}{\theta-\theta_{\min }}\right)} \\
& -c_{h m}\left\{\frac{1}{\theta} r p T-\frac{1}{\theta} n Q+\frac{1}{2} Q T n(n-2 r+1)\right\}-c_{h m} p\left(\frac{1}{2} r^{2} T^{2}-\frac{1}{\theta} r T+\frac{1}{p \theta} n Q\right) \\
& \left.-n i_{m p} s_{m p} M(1-\alpha) Q-c_{s m} p r T-n c_{t u}\left\{2-e^{-\beta\left(Q-Q_{0}\right)}\right\}\right] .
\end{aligned}
$$


Therefore, the average integrated profit $\operatorname{AIP}(n, r)$ is given by

$$
\begin{aligned}
\mathrm{AIP}= & \mathrm{APR}+\mathrm{APM}=\frac{1}{T}\left[\left(s_{r}-s_{m p}\right) Q+\frac{1}{2} s_{r} i_{d r} D_{c} M^{2}-c_{h r} T \frac{Q}{2}\right. \\
& \left.-s_{m p} i_{c m}(T-M)\left\{(1-\alpha) Q-\frac{1}{2} D_{c}(T+M)\right\}-A_{r}-i_{d r} s_{m p} \alpha Q(1-\alpha) T-c_{t r}(1-\alpha) Q\right] \\
& +\frac{1}{n T}\left[s_{m p} n Q+s_{m d}(p r T-n Q)+n s_{m p} i_{c m}(T-M)\left\{(1-\alpha) Q-\frac{1}{2} D_{c}(T+M)\right\}\right. \\
& +n s_{m p} i_{e m} \alpha Q(1-\alpha) T+n c_{t r}(1-\alpha) Q-\left\{p m_{0}+A+\delta p^{2}\right\} r T-\frac{B}{2} r^{2} T^{2} e^{k\left(\frac{\theta_{\max }-\theta}{\theta-\theta_{\min }}\right)} \\
& -c_{h m}\left\{\frac{1}{\theta} r p T-\frac{1}{\theta} n Q+\frac{1}{2} Q T n(n-2 r+1)\right\}-c_{h m} p\left(\frac{1}{2} r^{2} T^{2}-\frac{1}{\theta} r T+\frac{1}{p \theta} n Q\right) \\
& \left.-n i_{m p} s_{m p} M(1-\alpha) Q-c_{s m} p r T-n c_{t u}\left\{2-e^{-\beta\left(Q-Q_{0}\right)}\right\}\right]
\end{aligned}
$$

After substituting the values of $Q=D_{c} T$ and $T=1 / n$ in constraint equation $\frac{p}{\theta}\left(1-e^{-\theta r T}\right)=n Q$ as in Lemma 3.3, it becomes $\frac{p}{\theta}\left(1-e^{-\frac{\theta r}{n}}\right)=D_{c}$ which is an equation containing three variables $r, n$ and $\theta$. So, the average integrated profit AIP has been expressed as a function of $3-1=2$ independent variables $r$ and $n$ as follows

$$
\begin{aligned}
\operatorname{AIP}(r, n)= & \left(s_{r}-s_{m d}-\frac{1}{2} c_{h m}\right) D_{c}+\frac{1}{2 n} D_{c}\left\{s_{r} i_{d r} \alpha^{2}-c_{h r}-c_{h m}-2 s_{m p} i_{m p} \alpha(1-\alpha)\right\} \\
& -n A_{r}-n c_{t u}\left\{2-e^{-\beta\left(\frac{D_{c}}{n}-Q_{0}\right)}\right\}+\frac{r}{n}\left(s_{m d} p+c_{h m} D_{c}-p m_{0}-A-\delta p^{2}-c_{s m} p\right) \\
& -\frac{1}{2} c_{h m} p \frac{r^{2}}{n^{2}}-\frac{B r^{2}}{2 n^{2}} e^{k\left(\frac{\theta_{\max }-\theta}{\theta-\theta_{\min }}\right)} \\
\text { i.e., } \operatorname{AIP}(r, n)= & H+\frac{1}{n} G-n A_{r}-n c_{t u}\left\{2-e^{-\beta\left(\frac{D_{c}}{n}-Q_{0}\right)}\right\}+\frac{r}{n} L \\
& -\frac{1}{2} c_{h m} p \frac{r^{2}}{n^{2}}-\frac{B r^{2}}{2 n^{2}} e^{k\left(\frac{\theta_{\max }-\theta}{\theta-\theta_{\min }}\right)}
\end{aligned}
$$

where $H=\left(s_{r}-s_{m d}-\frac{1}{2} c_{h m}\right) D_{c}, G=\frac{1}{2} D_{c}\left\{s_{r} i_{d r} \alpha^{2}-c_{h r}-c_{h m}-2 s_{m p} i_{m p} \alpha(1-\alpha)\right\}$ and $L=s_{m d} p+c_{h m} D_{c}-$ $p m_{0}-A-\delta p^{2}-c_{s m} p$.

Considering the continuities of $r$ and $n$, the following first and second order derivatives of the average integrated profit function $\operatorname{AIP}(r, n)$ have been computed as follow.

$$
\begin{aligned}
\frac{\partial}{\partial r}\{\operatorname{AIP}(r, n)\}= & \frac{L}{n}-\frac{1}{n^{2}} c_{h m} p r-\frac{1}{n^{2}} B r e^{k\left(\frac{\theta_{\max }-\theta}{\theta-\theta_{\min }}\right)}+\frac{B k r^{2}}{2 n^{2}} \frac{\left(\theta_{\max }-\theta_{\min }\right)}{\left(\theta-\theta_{\min }\right)^{2}} \frac{\partial \theta}{\partial r} e^{k\left(\frac{\theta_{\max }-\theta}{\theta-\theta_{\min }}\right)} \\
= & \frac{L}{n}-\frac{1}{n^{2}} c_{h m} p r-\frac{B r}{n^{2}}\left\{1-\frac{k r}{2} \frac{\left(\theta_{\max }-\theta_{\min }\right)}{\left(\theta-\theta_{\min }\right)^{2}} \frac{\partial \theta}{\partial r}\right\} e^{k\left(\frac{\theta_{\max }-\theta}{\theta-\theta_{\min }}\right)}=\phi(r, n), \text { say } \\
\frac{\partial^{2}}{\partial r^{2}}\{\operatorname{AIP}(r, n)\}= & -\frac{1}{n^{2}} c_{h m} p-\frac{B}{n^{2}} e^{k\left(\frac{\theta_{\max }-\theta}{\theta-\theta_{\min }}\right)}+\frac{B k}{2 n^{2}} \frac{\left(\theta_{\max }-\theta_{\min }\right)}{\left(\theta-\theta_{\min }\right)^{2}}\left\{4 r \frac{\partial \theta}{\partial r}-\frac{2 r^{2}}{\left(\theta-\theta_{\min }\right)}\left(\frac{\partial \theta}{\partial r}\right)^{2}\right. \\
& \left.-k r^{2} \frac{\left(\theta_{\max }-\theta_{\min }\right)}{\left(\theta-\theta_{\min }\right)^{2}}\left(\frac{\partial \theta}{\partial r}\right)^{2}+r^{2} \frac{\partial^{2} \theta}{\partial r^{2}}\right\} e^{k\left(\frac{\theta_{\max }-\theta}{\theta-\theta_{\min }}\right)} \\
\frac{\partial}{\partial n}\{\operatorname{AIP}(r, n)\}= & -\frac{G}{n^{2}}-A_{r}-c_{t u}\left\{2-e^{-\beta\left(\frac{D_{c}}{n}-Q_{0}\right)}\right\}+\frac{c_{t u} \beta D_{c}}{n} e^{-\beta\left(\frac{D_{c}}{n}-Q_{0}\right)}-\frac{r L}{n^{2}}+\frac{c_{h m} p r^{2}}{n^{3}}
\end{aligned}
$$




$$
\begin{aligned}
& +\frac{B r^{2}}{n^{3}} e^{k\left(\frac{\theta_{\max }-\theta}{\theta-\theta_{\min }}\right)}+\frac{B k r^{2}}{2 n^{2}} \frac{\left(\theta_{\max }-\theta_{\min }\right)}{\left(\theta-\theta_{\min }\right)^{2}} \frac{\partial \theta}{\partial n} e^{k\left(\frac{\theta_{\max }-\theta}{\theta-\theta_{\min }}\right)}=\psi(r, n), \text { say } \\
& \frac{\partial^{2}}{\partial n^{2}}\{\operatorname{AIP}(r, n)\}=\frac{2 G}{n^{3}}+\frac{c_{t u} \beta^{2} D_{c}^{2}}{n^{3}} e^{-\beta\left(\frac{D_{c}}{n}-Q_{0}\right)}+\frac{2 r L}{n^{3}}-\frac{3 c_{h m} p r^{2}}{n^{4}}-\frac{3 B r^{2}}{n^{4}} e^{k\left(\frac{\theta_{\max }-\theta}{\theta-\theta_{\min }}\right)} \\
& -\frac{B k r^{2}}{2} \frac{\left(\theta_{\max }-\theta_{\min }\right)}{\left(\theta-\theta_{\min }\right)^{2}}\left\{\frac{2}{n^{2}\left(\theta-\theta_{\min }\right)}\left(\frac{\partial \theta}{\partial n}\right)^{2}+\frac{4}{n^{3}} \frac{\partial \theta}{\partial n}\right. \\
& \left.+\frac{k}{n^{2}} \frac{\left(\theta_{\max }-\theta_{\min }\right)}{\left(\theta-\theta_{\min }\right)^{2}}\left(\frac{\partial \theta}{\partial n}\right)^{2}-\frac{1}{n^{2}} \frac{\partial^{2} \theta}{\partial n^{2}}\right\} e^{k\left(\frac{\theta_{\max }-\theta}{\theta-\theta_{\min }}\right)} \\
& \frac{\partial^{2}}{\partial r \partial n}\{\operatorname{AIP}(r, n)\}=-\frac{L}{n^{2}}+\frac{2 c_{h m} p r}{n^{3}}+\frac{B r}{n^{3}}\left\{2-k r \frac{\left(\theta_{\max }-\theta_{\min }\right)}{\left(\theta-\theta_{\min }\right)^{2}} \frac{\partial \theta}{\partial r}\right\} e^{k\left(\frac{\theta_{\max }-\theta}{\theta-\theta_{\min }}\right)} \\
& +\frac{B k r}{2 n^{2}} \frac{\left(\theta_{\max }-\theta_{\min }\right)}{\left(\theta-\theta_{\min }\right)^{2}}\left\{2 \frac{\partial \theta}{\partial n}-\frac{2 r}{\left(\theta-\theta_{\min }\right)} \frac{\partial \theta}{\partial r} \frac{\partial \theta}{\partial n}\right. \\
& \left.-k r \frac{\left(\theta_{\max }-\theta_{\min }\right)}{\left(\theta-\theta_{\min }\right)^{2}} \frac{\partial \theta}{\partial r} \frac{\partial \theta}{\partial n}+r \frac{\partial^{2} \theta}{\partial r \partial n}\right\} e^{k\left(\frac{\theta_{\max }-\theta}{\theta-\theta_{\min }}\right)} \\
& \frac{\partial^{2}}{\partial n \partial r}\{\operatorname{AIP}(r, n)\}=-\frac{L}{n^{2}}+\frac{2 c_{h m} p r}{n^{3}}+\frac{B r}{n^{2}}\left\{\frac{2}{n}+k \frac{\left(\theta_{\max }-\theta_{\min }\right)}{\left(\theta-\theta_{\min }\right)^{2}} \frac{\partial \theta}{\partial n}\right\} e^{k\left(\frac{\theta_{\max }-\theta}{\theta-\theta_{\min }}\right)} \\
& -\frac{B k r^{2}}{2 n^{2}} \frac{\left(\theta_{\max }-\theta_{\min }\right)}{\left(\theta-\theta_{\min }\right)^{2}}\left\{\frac{2}{n} \frac{\partial \theta}{\partial r}+\frac{2}{\left(\theta-\theta_{\min }\right)} \frac{\partial \theta}{\partial r} \frac{\partial \theta}{\partial n}\right. \\
& \left.+k \frac{\left(\theta_{\max }-\theta_{\min }\right)}{\left(\theta-\theta_{\min }\right)^{2}} \frac{\partial \theta}{\partial r} \frac{\partial \theta}{\partial n}-\frac{\partial^{2} \theta}{\partial n \partial r}\right\} e^{k\left(\frac{\theta_{\max }-\theta}{\theta-\theta_{\min }}\right)}
\end{aligned}
$$

where $\frac{\partial \theta}{\partial r}=\frac{\theta e^{-\frac{\theta r}{n}}}{\frac{n D_{c}}{p}-r e^{-\frac{\theta r}{n}}}, \frac{\partial^{2} \theta}{\partial r^{2}}=\frac{1}{\left(\frac{n D_{c}}{p}-r e^{-\frac{\theta r}{n}}\right)^{2}}\left[\frac{n D_{c}}{p}\left\{\left(1-\frac{\theta r}{n}\right) \frac{\partial \theta}{\partial r}-\frac{\theta^{2}}{n}\right\}-\left(r \frac{\partial \theta}{\partial r}-\theta\right) e^{-\frac{\theta r}{n}}\right] e^{-\frac{\theta r}{n}}, \frac{\partial \theta}{\partial n}=$ $\frac{1}{\frac{r}{n} e^{-\frac{\theta r}{n}}-\frac{D_{c}}{p}}\left\{\frac{\theta r}{n^{2}} e^{-\frac{\theta r}{n}}\right\}, \quad \frac{\partial^{2} \theta}{\partial n^{2}}=\frac{1}{\left(\frac{r}{n} e^{-\frac{\theta r}{n}}-\frac{D_{c}}{p}\right)^{2}}\left[\left(\frac{\partial \theta}{\partial n}-\frac{\theta}{n}\right) \frac{r^{2}}{n^{3}} e^{-\frac{\theta r}{n}}-\frac{D_{c}}{p}\left\{\left(1-\frac{\theta r}{n}\right) \frac{r}{n^{2}} \frac{\partial \theta}{\partial n}-\left(2-\frac{\theta r}{n}\right) \frac{\theta r}{n^{3}}\right\}\right] e^{-\frac{\theta r}{n}}$, $\frac{\partial^{2} \theta}{\partial n \partial r}=\frac{1}{\left(\frac{n D_{c}}{p}-r e^{-\frac{\theta r}{n}}\right)^{2}}\left[\frac{n D_{c}}{p}\left\{\left(1-\frac{\theta r}{n}\right) \frac{\partial \theta}{\partial n}+\frac{\theta^{2} r}{n^{2}}\right\}-r \frac{\partial \theta}{\partial n} e^{-\frac{\theta r}{n}}-\frac{\theta D_{c}}{p}\right] e^{-\frac{\theta r}{n}} \quad$ and $\quad \frac{\partial^{2} \theta}{\partial r \partial n} \quad=$ $\frac{1}{\left(r e^{-\frac{\theta r}{n}}-\frac{n D_{c}}{p}\right)^{2}}\left[\frac{r^{2}}{n} \frac{\partial \theta}{\partial r} e^{-\frac{\theta r}{n}}-\frac{n D_{c}}{p}\left(1-\frac{\theta r}{n}\right)\left(\frac{\theta}{n}+\frac{r}{n} \frac{\partial \theta}{\partial r}\right)\right] e^{-\frac{\theta r}{n}}$ are obtained from the equation $\frac{p}{\theta}\left(1-e^{-\frac{\theta r}{n}}\right)=D_{c}$ by considering $\theta$ is a function of $r$ and $n$.

Proposition 3.5. If $\left(r^{*}, n^{*}\right)$ be the positive root of the system of equations $\phi(r, n)=0$ and $\psi(r, n)=0$, then it be the optimum solution provided that $(i)$ both $\frac{\partial^{2}}{\partial r^{2}}\{\operatorname{AIP}(r, n)\}$ and $\frac{\partial^{2}}{\partial n^{2}}\{\operatorname{AIP}(r, n)\}$ are negative and $($ ii $)$ $\frac{\partial^{2}}{\partial r^{2}}\{\operatorname{AIP}(r, n)\} \frac{\partial^{2}}{\partial n^{2}}\{\operatorname{AIP}(r, n)\}-\left[\frac{\partial^{2}}{\partial n \partial r}\{\operatorname{AIP}(r, n)\}\right]^{2}>0$.

\section{Solution Methodology}

In this section, to obtain the optimum profit of $\operatorname{AIP}(r, n)$ a solution procedure has been introduced. As, the independent variables $r$ and $n$ are integer, so it is not possible to optimize directly. In this case, the following steps have been adopted:

(i) The decision variables $r$ and $n$ have been considered as continuous.

(ii) After that the Solution methodology 1 has been adopted to optimize $\operatorname{AIP}(r, n)$. 
(iii) If the solutions obtained in step (ii) are integers, then that solutions are treated as optimum integer solutions and we evaluate associated average integrated profit $\operatorname{AIP}^{*}\left(r^{*}, n^{*}\right)$. Otherwise, if any one or both of $r^{*}$ and $n^{*}$ are not integers, the branch and bound technique has been used to obtain optimum integer solutions of this proposed model by Solution methodology 2 .

\subsection{Solution methodology 1: To find the solution of $r$ and $n$ as real number}

It is observed from equation (3.12) that the average integrated profit $\operatorname{AIP}(r, n)$ is highly non-linear. Hence to obtain the optimal solution the following algorithms have been developed.

Algorithm 4.1. For any particular value of $u$, say $u=u_{0}$, the value of $v$ can be found from the equation $\varphi(u, v)=0$ as follows:

Step 1: For $u=u_{0}$, compute $\varphi\left(u_{0}, v\right)=0$.

Step 2: Choose $v_{1}$ and $v_{2}$ in such a way that $\varphi\left(u_{0}, v_{1}\right) \varphi\left(u_{0}, v_{2}\right)<0$. Then according to Roll's theorem there must exist at least a root of $\varphi\left(u_{0}, v\right)=0$, lies between $v_{1}$ and $v_{2}$.

Step 3: Compute the midpoint $\xi$ of the interval $\left(v_{1}, v_{2}\right)$, i.e., $\xi=\frac{\left(v_{1}+v_{2}\right)}{2}$.

Step 4: Compute the signs of $\varphi\left(u_{0}, v_{1}\right), \varphi\left(u_{0}, \xi\right)$, and $\varphi\left(u_{0}, v_{2}\right)$.

Step 5: If $\varphi\left(u_{0}, v_{1}\right) \varphi\left(u_{0}, \xi\right)<0$, then there must exist a root of $\varphi\left(u_{0}, v\right)=0$ lies between $v_{1}$ and $\xi$. Then replace $\xi$ by $v_{2}$. Otherwise, a root of $\varphi\left(u_{0}, v\right)=0$ lies between $\xi$ and $v_{2}$, then replace $\xi$ by $v_{1}$.

Step 6: Repeat steps 3 through 5 until $\left|v_{1}-v_{2}\right|<10^{-\varepsilon}$ where $\varepsilon$ is a tolerance limit.

Step 7: Then the root of $\varphi\left(u_{0}, v\right)=0$ is $\xi$ such that $\xi=\frac{\left(v_{1}+v_{2}\right)}{2}$.

Algorithm 4.2. As the equations $\phi(r, n)=0$ and $\psi(r, n)=0$ are highly non-linear, it is very difficult to obtain the general explicit solution. So, to obtain the average integrated profit $\operatorname{AIP}(r, n)$ of the proposed model following steps have been computed. Here, $r^{*}, n^{*}, T^{*}, \theta^{*}, Q^{*}, \mathrm{APR}^{*}, \mathrm{APM}^{*}$ and $\operatorname{AIP}^{*}\left(r^{*}, n^{*}\right)$ are respectively denoted the optimal values of $r, n, T, \theta, Q, \operatorname{APR}, \operatorname{APM}$ and $\operatorname{AIP}(r, n)$.

Step 1: Select an interval $\left(r_{10}, r_{11}\right)$ where $r_{10} \in\left(0, r_{0}\right)$ and $r_{11} \in\left(0, r_{0}\right)$ and $r \leq r_{0}$ where $r_{0}$ is also considered as initial value.

Step 2: Compute $n_{0 \phi}, n_{1 \phi}, n_{0 \psi}$ and $n_{1 \psi}$ for $n$ from $\phi\left(r_{10}, n\right)=0, \phi\left(r_{11}, n\right)=0, \psi\left(r_{10}, n\right)=0$ and $\psi\left(r_{11}, n\right)=0$ respectively by Algorithm 4.1.

Step 3: Compute $\triangle_{r_{10}}=n_{0 \phi}-n_{0 \psi}$ and $\triangle_{r_{11}}=n_{1 \phi}-n_{1 \psi}$.

Step 4: If $\triangle_{r_{10}} \triangle_{r_{11}}<0$, i.e., the signs of $\triangle_{r_{10}}$ and $\triangle_{r_{11}}$ are opposite in sign, then compute $r_{1 \xi}=\frac{\left(r_{10}+r_{11}\right)}{2}$.

Step 5: Compute $n_{1 \xi \phi}$ and $n_{1 \xi \psi}$ for $n$ from $\phi\left(r_{1 \xi}, n\right)=0$ and $\psi\left(r_{1 \xi}, n\right)=0$ respectively by Algorithm 4.1.

Step 6: Calculate $\triangle_{r_{1 \xi}}=n_{1 \xi \phi}-n_{1 \xi \psi}$.

Step 7: Compare $\triangle_{r_{1 \xi}}$ with $\triangle_{r_{10}}$. If $\triangle_{r_{10}} \triangle_{r_{1 \xi}}<0$, i.e., the signs of $\triangle_{r_{10}}$ and $\triangle_{r_{1 \xi}}$ are opposite in sign, then replace $r_{11}$ by $r_{1 \xi}$. Otherwise replace $r_{10}$ by $r_{1 \xi}$.

Step 8: Repeat steps 4 through 7 until the absolute values of $\left(r_{10}-r_{1 m}\right)$ or $\left(\triangle_{r_{10}}-\triangle_{r_{1 \xi}}\right)$ or $\left(\triangle_{r_{11}}-\triangle_{r_{1 \xi}}\right)$ are within the tolerance limits.

Step 9: The root of $\phi(r, n)=0$ and $\psi(r, n)=0$ is $\left(r^{m}, n^{m}\right)$ where $r^{m}=r_{1 \xi}$ and $n^{m}=\frac{n_{0 \phi}+n_{1 \phi}}{2}$ or $\frac{n_{0 \psi}+n_{1 \psi}}{2}, r^{m}$ and $n^{m}$ are the $m$-th approximate root of $r$ and $n$.

Step 10: Compute $\triangle_{1}, \triangle_{2}$ and $\triangle_{3}$ at the point $\left(r^{m}, n^{m}\right)$ where $\Delta_{1}=\frac{\partial}{\partial r}\{\phi(r, n)\}=\frac{\partial^{2}}{\partial r^{2}}\{\operatorname{AIP}(r, n)\}, \Delta_{2}=$ $\frac{\partial}{\partial n}\{\psi(r, n)\}=\frac{\partial^{2}}{\partial n^{2}}\{\operatorname{AIP}(r, n)\}$ and $\Delta_{3}=\frac{\partial}{\partial n}\{\phi(r, n)\}=\frac{\partial^{2}}{\partial n \partial r}\{\operatorname{AIP}(r, n)\}$.

Step 11: If $\Delta_{1}<0, \Delta_{2}<0$ and $\Delta_{1} \Delta_{2}>\Delta_{3}^{2}$, then according Proposition 3.5, $\left(r^{m}, n^{m}\right)$ be the optimal solution. So $r^{*}=r^{m}, n^{*}=n^{m}$ and calculate $T^{*}$ by $T=\frac{1}{n}, \theta^{*}$ by equation (3.3), $Q^{*}$ by equation $Q=D_{c} T$. Also calculate $\mathrm{APR}^{*}, \mathrm{APM}^{*}$ and $\mathrm{AIP}^{*}\left(r^{*}, n^{*}\right)$ respectively from equations (3.2), (3.8) and (3.10).

Step 12: If $\Delta_{1}>0$ and $\Delta_{2}<0$ or $\Delta_{1}<0$ and $\Delta_{2}>0$ or $\Delta_{1} \Delta_{2}-\Delta_{3}^{2}<0$, then $\left(r^{m}, n^{m}\right)$ is not optimal solution. In this case, goto step 2 and change the value of $\left(r_{10}, r_{11}\right)$.

Step 13: Print the optimal values $r^{*}, n^{*}, T^{*}, \theta^{*}, Q^{*}, \mathrm{APR}^{*}, \mathrm{APM}^{*}$ and $\operatorname{AIP}^{*}\left(r^{*}, n^{*}\right)$. 


\subsection{Solution methodology 2: To obtain integer solution with Branch and Bound Technique}

This is a division and conquer method in which a large problem is to be divided into some smaller ones known as the branch part. The conquering part shows how good a solution can be obtained from each smaller sub-problems and to do this, the problem is to be divided further until a problem is obtained that can be handled, known as bound part.

For an integer programming model (IPM), the programming model that can be obtained by dropping the requirement that all the variables should be integers, is known as the programming relaxation of the IPM.

\section{Branch and Bound Algorithm}

Step 1: Chose an integer programming problem (IPM).

Step 2: Obtain the optimum solution to the selected IPM by the programming relaxation.

Two cases arise:

(i) Either there is no feasible solution, then stop.

or (ii) The problem has an optimum solution, then go to step 3.

Step 3: If the optimum solution obtained in step 2, satisfies integer constraints, then note it. If it has no integer optimum solution, then go to step 4.

Step 4: Select any variable whose value is not an integer obtained as an optimum solution in step 1. Suppose, $y^{*}$ denotes the optimum value of that variable $y$. Again create two subproblems of the selected problem. These two subproblems are identical with the problem as selected in step 1, except that, in one, the lower bound of $y$ is replaced by $\left[y^{*}\right]+1$ and in the other, the upper bound of $y$ is replaced by $\left[y^{*}\right]$, where $[y]$ indicates the greatest integer $\leq y$; then return to step 1 .

Step 5: At the termination of the algorithm, take the best optimum solution from the all recorded integer valued optimum solutions in step 3. Otherwise if there does not exist any feasible integer valued solution that optimizes the IPM, then there does not exist integer valued feasible solution of that IPM.

\section{NumeriCAL ILLUSTRATION}

In this section, we illustrate some numerical examples to study the feasibility of the proposed integrated model. The values of the parameters of the model have been seemed to be realistic. Following examples have been solved to find out the optimal number of production cycle $r$, number of replenishment cycle $n$, and hence the optimum values of the replenishment cycle time $T$, replenishment quantity $Q$ and system reliability parameter $\theta$ along with the optimal average integrated profit $\operatorname{AIP}(r, n)$ of the model.

Example 5.1. A manufacturing company produces an item at a constant production rate $p$ units/year to satisfy the customers constant demand $D_{c}$ units/year throughout the business period of $n T=1$ year, retailer's selling price per unit perfect item, $s_{r}=\$ 150$. To maintain the reliability of the manufacturing system, a development cost for production has been considered according to assumption (xv) where $A=\$ 100, B=\$ 600$, $k=0.01, \theta_{\min }=0.01$ and $\theta_{\max }=0.9$. The material cost is $m_{0}=\$ 20$ and the unit production cost has been decided according to assumption (xvii) where $\delta=\$ 0.2$. Here, the manufacturer has determined to sell the produced perfect items at price $s_{m p}=\$ 130$ and offers a credit period $M=\alpha T$ year according to assumption (v) to retailer in such a condition that he will have to pay in advance $\alpha$ part of the purchased cost of the replenishment quantity $Q$ units prior to $(1-\alpha) T$ year of time of replenishment and he will be exempted of interest charge up-to the credit period but will have to pay an additional interest charged by the manufacturer at the rate of $i_{c m}=3 \%$ on the remaining stock of the left replenishment quantity $(1-\alpha) Q$ units after the credit period and also has considered free transportation on advance payment quantity $\alpha Q$ units. Retailer achieve an interest from the sales revenue at the rate of $i_{d r}=3 \%$. Manufacturer's holding cost of per unit finished item per year is $c_{h m}=\$ 0.5$, retailer's holding cost is $c_{h r}=\$ 0.6$ per item per year. To find the optimum number of production cycle $r$, optimum number of replenishment cycle $n$ and hence replenishment cycle time $T$ years, the reliability parameter $\theta$ the replenishment quantity $Q$ that maximize the integrated profit. 
TABLE 2. Input data of different parameters.

\begin{tabular}{llllllll}
\hline \hline Parameter & Value & Parameter & Value & Parameter & Value & Parameter & Value \\
\hline$s_{r}$ & 150 & $p$ & 190 & $m_{0}$ & 20 & $i_{d r}$ & 0.03 \\
$s_{m p}$ & 130 & $c_{t r}$ & 0.2 & $c_{t u}$ & 2 & $i_{m p}$ & 0.03 \\
$s_{m d}$ & 25 & $\delta$ & 0.02 & $\theta_{\max }$ & 0.9 & $i_{c m}$ & 0.03 \\
$c_{h r}$ & 0.6 & $\beta$ & 0.2 & $\theta_{\min }$ & 0.01 & $A_{r}$ & 1 \\
$c_{h m}$ & 0.5 & $k$ & 0.01 & $\alpha$ & 0.2 & $A$ & 100 \\
$c_{s m}$ & 0.5 & $D_{c}$ & 150 & $Q_{0}$ & 10 & $B$ & 600 \\
\hline
\end{tabular}

TABLE 3. Optimal results of the illustrated model when $\alpha=0.2$.

\begin{tabular}{|c|c|c|c|c|c|c|c|}
\hline $\begin{array}{l}\text { Number of } \\
\text { Production } \\
\text { cycle } \\
\left(r^{*}\right) \\
\end{array}$ & $\begin{array}{l}\text { Number } \\
\text { of reple- } \\
\text { nishment } \\
\left(n^{*}\right)\end{array}$ & $\begin{array}{l}\text { Replenishment } \\
\text { cycle } \\
\text { time } \\
\left(T^{*}\right) \\
\end{array}$ & $\begin{array}{l}\text { System } \\
\text { reliability } \\
\text { parameter } \\
\left(\theta^{*}\right)\end{array}$ & $\begin{array}{l}\text { Replenish- } \\
\text { ment } \\
\text { quantity } \\
\left(Q^{*}\right) \\
\end{array}$ & $\begin{array}{l}\text { Retailer's } \\
\text { average } \\
\text { profit } \\
\text { APR }^{*} \\
\end{array}$ & $\begin{array}{l}\text { Manufacturer's } \\
\text { average } \\
\text { Profit } \\
\text { APM }^{*}\end{array}$ & $\begin{array}{l}\text { Average } \\
\text { integrated } \\
\text { profit } \\
\operatorname{AIP}^{*}\left(r^{*}, n^{*}\right) \\
\end{array}$ \\
\hline 5 & 6 & 0.167 & 0.131 & 25 & 2933.55 & 15557.45 & 18491 \\
\hline
\end{tabular}

TABLE 4. Optimal results of the illustrated model when $\alpha=0$.

\begin{tabular}{|c|c|c|c|c|c|c|c|}
\hline $\begin{array}{l}\text { Number of } \\
\text { Production } \\
\text { cycle } \\
\left(r^{*}\right)\end{array}$ & $\begin{array}{l}\text { Number } \\
\text { of reple- } \\
\text { nishment } \\
\left(n^{*}\right)\end{array}$ & $\begin{array}{l}\text { Replenishment } \\
\text { cycle } \\
\text { time } \\
\left(T^{*}\right)\end{array}$ & $\begin{array}{l}\text { System } \\
\text { parameter } \\
\text { parameter } \\
\left(\theta^{*}\right)\end{array}$ & $\begin{array}{l}\text { Replenish- } \\
\text { ment } \\
\text { quantity } \\
\left(Q^{*}\right)\end{array}$ & $\begin{array}{l}\text { Retailer's } \\
\text { average } \\
\text { profit } \\
\text { APR }^{*}\end{array}$ & $\begin{array}{l}\text { Manufacturer's } \\
\text { average } \\
\text { Profit } \\
\text { APM }^{*}\end{array}$ & $\begin{array}{l}\text { Average } \\
\text { integrated } \\
\text { profit } \\
\operatorname{AIP}^{*}\left(r^{*}, n^{*}\right)\end{array}$ \\
\hline 11 & 13 & 0.0769 & 0.1658205 & 11.54 & 2931.04 & 15561.45 & 18492.49 \\
\hline
\end{tabular}

Solution: In this problem, the input values of the necessary parameters are given in Table 2.

Considering $r$ and $n$ are continuous variables and with the help of Solution methodology 1, it has been obtained that $r=5.06$ and $n=6.11$ which are not integers. So, to obtain optimum integer solution of the above problem Branch and Bound Technique has been applied. Optimum solutions $r^{*}$ and $n^{*}$ and corresponding optimal average integrated profit $\operatorname{AIP}^{*}(r, n)$, as obtained with the help of above technique, have been presented in Table 3 .

The result in Table 3 shows that the manufacturer has to be produced the items upto 5 number of cycles and has to be replenished the produced items to the retailer's door in 6 number of cycle to achieve the optimum average integrated profit.

Example 5.2. In this example, using the same data as in Example 5.1 except $\alpha$ is taken as zero. That is, the case where no advance payment is made by the retailer and consequently neither credit period nor free transportation on the advance payment quantity has been offered by the manufacturer. So, in this case, the credit period $M=\alpha T=0$, retailer's average interest earned from the Bank due to delay payment RAIE $=0$, retailer's average interest loss due to advance payment RAILAP $=0$, manufacturer's opportunity loss for offering credit period MOLDP $=0$, interest earned by the manufacturer due to $\alpha$ part advance payment of the replenishment quantity $Q$ prior to $(1-\alpha) T$ time of replenishment is MIEAP $=0$. The result has been given in Table 4.

From above two examples it is seen that the retailer's average profit (APR $=2933.55$ ) (when advance payment is made) is higher than the retailer's average profit $(\mathrm{APR}=2931.04)$ when there is no advance payment. So, 
TABLE 5. Sensitivity analysis with respect to a part of the advance payment $\alpha$.

\begin{tabular}{lllllllllll}
\hline \hline$\alpha$ & $r^{*}$ & $n^{*}$ & RAIE & RAILAP & RATC & RAICM & MAOL & APR $^{*}$ & APM $^{*}$ & AIP $^{*}$ \\
\hline 0.01 & 5 & 6 & 0.0056 & 0.96 & 29.7 & 46.81 & 0.96 & 2909.03 & 15594.37 & 18503.39 \\
0.03 & 5 & 6 & 0.051 & 2.84 & 29.1 & 46.03 & 2.84 & 2911.58 & 15589.98 & 18501.56 \\
0.05 & 5 & 6 & 0.15 & 4.63 & 28.5 & 39.37 & 4.63 & 2914.14 & 15585.72 & 18499.86 \\
0.07 & 5 & 6 & 0.28 & 6.35 & 27.9 & 35.82 & 6.35 & 2916.71 & 15581.57 & 18498.28 \\
0.09 & 5 & 6 & 0.46 & 7.98 & 27.3 & 32.38 & 7.99 & 2919.29 & 15577.54 & 18496.82 \\
0.11 & 5 & 6 & 0.68 & 9.55 & 26.7 & 29.07 & 9.55 & 2921.87 & 15573.62 & 18495.49 \\
0.13 & 5 & 6 & 0.95 & 11.03 & 26.1 & 25.87 & 11.03 & 2924.45 & 15569.82 & 18494.27 \\
0.15 & 5 & 6 & 1.27 & 12.43 & 25.5 & 22.79 & 12.43 & 2927.04 & 15566.14 & 18493.19 \\
0.17 & 5 & 6 & 1.63 & 13.76 & 24.9 & 19.83 & 13.76 & 2929.64 & 15562.58 & 18492.22 \\
0.19 & 5 & 6 & 2.03 & 15.00 & 24.3 & 16.98 & 15.00 & 2932.25 & 15559.13 & 18491.38 \\
0.21 & 5 & 6 & 2.48 & 16.18 & 23.7 & 14.25 & 16.18 & 2934.84 & 15555.80 & 18490.66 \\
0.23 & 5 & 6 & 2.98 & 17.27 & 23.1 & 11.64 & 17.27 & 2937.47 & 15552.59 & 18490.06 \\
\hline
\end{tabular}
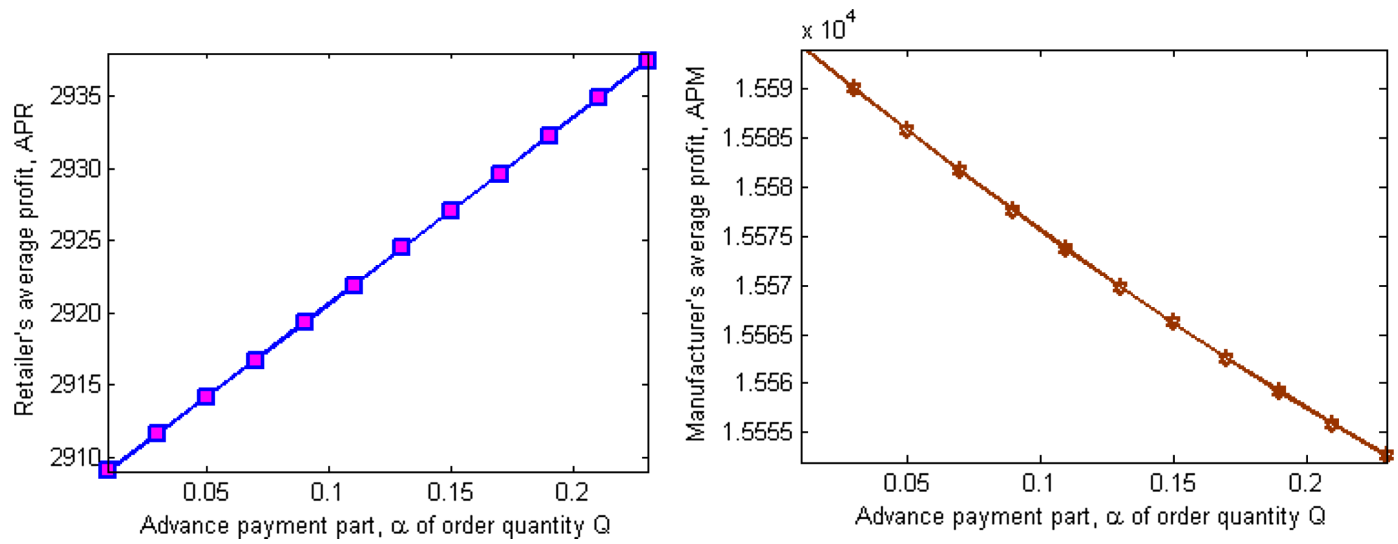

FigURE 4. Retailer's profit APR and Manufacturer's profit APM w.r.t. $\alpha$.

by this proposed model, the retailer can be motivated to prepay a specified part of the purchasing cost of the replenishment quantity prior to replenish the product to enable him to acquire higher profit.

\section{SENSITIVITY ANALYSIS}

\section{Sensitivity analysis 1}

In this case, using the same data as those in Example 5.1 except the advance payment part $\alpha$. The results are displayed in Table 5 .

It is seen from Table 5 and Figure 4 that as advance payment part increases, retailer's average profit increases and both manufacturer's average profit as well as average integrated profit decreases because both retailer's average transportation cost (RATC) and interest charged by the manufacturer (RAICM) decreases whereas retailer's average interest earn (RAIE) increases.

\section{Sensitivity analysis 2}

In this case, using the same data as those in Example 5.1 where we study the sensitivity of different parameters. The results are given in Table 6. 
TABLE 6. Sensitivity analysis with respect to different parameters.

\begin{tabular}{llllllllll}
\hline \hline Parameter & $r^{*}$ & $n^{*}$ & $M$ & $T$ & $\theta$ & $Q$ & APR & APM & AIP \\
\hline$Q_{0}$ & & & & & & & & & \\
8 & 15 & 18 & 0.011 & 0.055 & 0.1309522 & 8.33 & 2945.85 & 15536.30 & 18482.15 \\
9 & 5 & 6 & 0.033 & 0.167 & 0.1309520 & 25 & 2933.55 & 15557.34 & 18490.89 \\
10 & 5 & 6 & 0.033 & 0.167 & 0.1309520 & 25 & 2933.55 & 15557.45 & 18491.00 \\
11 & 5 & 6 & 0.033 & 0.167 & 0.1309520 & 25 & 2933.55 & 15557.58 & 18491.13 \\
12 & 10 & 12 & 0.017 & 0.083 & 0.1309522 & 12.5 & 2945.77 & 15549.89 & 18495.67 \\
13 & 9 & 11 & 0.018 & 0.091 & 0.0878369 & 13.64 & 2945.12 & 15550.62 & 18495.74 \\
$p$ & & & & & & & & & \\
185 & 12 & 14 & 0.014 & 0.071 & 0.1308864 & 10.71 & 2946.38 & 15545.34 & 18491.72 \\
187 & 5 & 6 & 0.033 & 0.167 & 0.092154 & 25 & 2933.55 & 15557.72 & 18491.27 \\
189 & 5 & 6 & 0.033 & 0.167 & 0.1180643 & 25 & 2933.55 & 15558.23 & 18491.78 \\
191 & 5 & 6 & 0.033 & 0.167 & 0.1437957 & 25 & 2933.55 & 15556.24 & 18489.79 \\
193 & 9 & 11 & 0.018 & 0.091 & 0.1267001 & 13.64 & 2945.12 & 15541.95 & 18487.07 \\
195 & 12 & 15 & 0.013 & 0.067 & 0.098 & 10 & 2946.42 & 15542.49 & 187488.91 \\
$D_{c}$ & & & & & & & & & \\
145 & 4 & 5 & 0.04 & 0.2 & 0.1188079 & 29 & 2829.52 & 15050.73 & 17880.25 \\
147 & 9 & 11 & 0.018 & 0.091 & 0.1379934 & 13.36 & 2885.00 & 15236.19 & 18122.18 \\
149 & 5 & 6 & 0.033 & 0.167 & 0.1473220 & 24.83 & 2913.95 & 15454.02 & 18367.77 \\
151 & 5 & 6 & 0.033 & 0.167 & 0.1147284 & 25.17 & 2953.15 & 15660.28 & 18613.42 \\
153 & 6 & 7 & 0.029 & 0.143 & 0.1472310 & 21.86 & 2996.65 & 15858.83 & 18855.49 \\
155 & 6 & 7 & 0.029 & 0.143 & 0.1163460 & 22.14 & 3035.92 & 16065.12 & 19101.03 \\
\hline
\end{tabular}

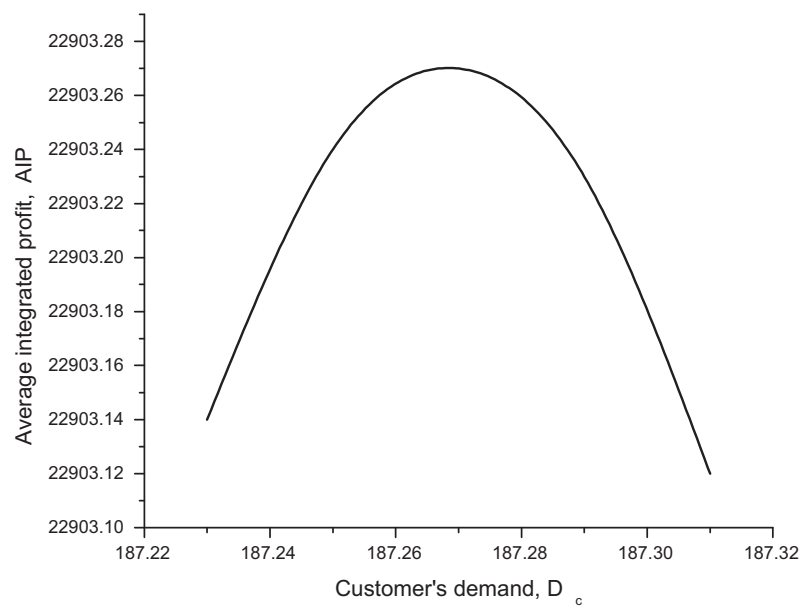

Figure 5. AIP vs. $D_{c}$ when $r=7$ and $n=7$ remain same as $D_{c}$ changes.

From Table 6, it explores that the average integrated profit (AIP) as well as manufacturer's average profit (APM) increase but the retailer's average profit (APR) keeps same when minimum replenishment quantity $Q_{0}$ increases whenever the number of production cycle $r$ and the number of replenishment cycle $n$ remains sane as $Q_{0}$ increases. It is also observe that whenever $r$ and $n$ increase as $Q_{0}$ increases, the retailer's average profit (APR) increases because in that case, holding cost for retailer decreases.

Figure 5 reveals that the average integrated profit $\operatorname{AIP}(r, n)$ increases as the customer's demand $D_{c}$ increases and after getting its maximum value it decreases although the customer's demand $D_{c}$ increases. As in this 


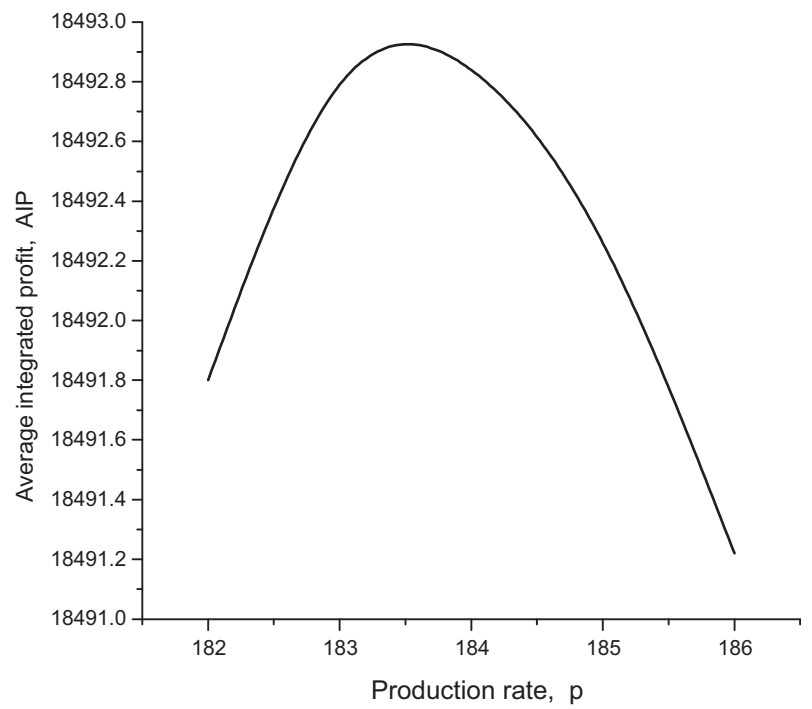

Figure 6. AIP vs. $p$ whenever $r=6$ and $n=7$ remains same as $p$ changes.

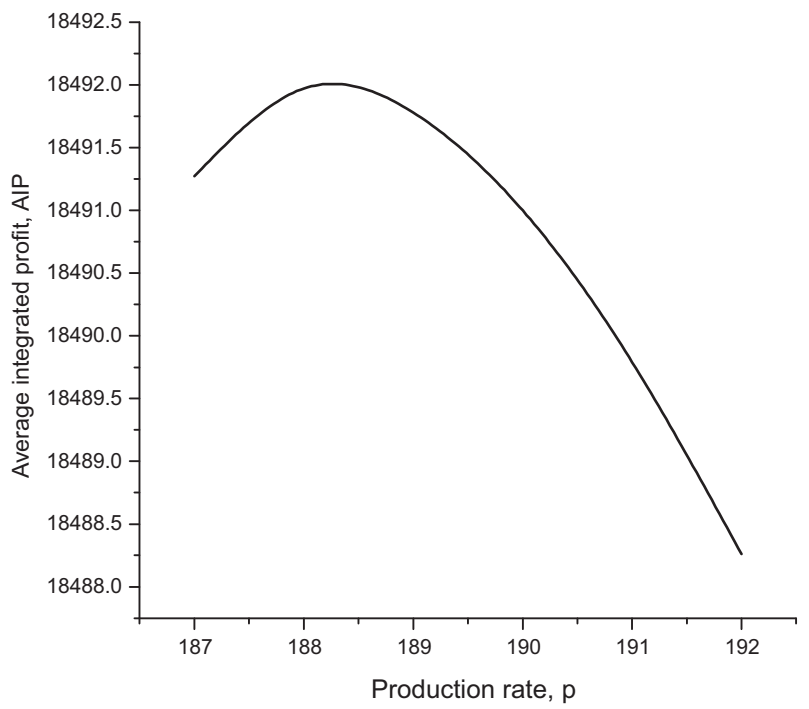

FIgURE 7. AIP vs. $p$ whenever $r=5$ and $n=6$ remains same as $p$ changes.

case, number of production cycle $r$ and number of replenishment cycle $n$ are fixed, to satisfy more customer's demand, the manufacturing system should be made more reliable by introducing more development cost. For this reason, average integrated profit decreases though the customer's demand $D_{c}$ increases.

Figures 6 and 7 reveals that there exist several local optimum production rate $p$ for several ranges of production rate and it is also seen that in case of less optimum production rate, the average integrated profit is higher than that in the case of higher optimum production rate. Reason is that, to reduce the holding cost, in case of less optimum production rate, both the number of production cycle $r$ and number of replenishment cycle $n$ are 
TABLE 7. Sensitivity analysis with respect to development cost parameter $B$ when $k=0.01$.

\begin{tabular}{lllllllll}
\hline \hline $\begin{array}{l}\text { Development } \\
\text { cost }\end{array}$ & $\begin{array}{l}\text { Total } \\
\text { development }\end{array}$ & $\begin{array}{l}\text { Production } \\
\text { cycle }\end{array}$ & $\begin{array}{l}\text { Replenishment } \\
\text { cycle }\end{array}$ & $\begin{array}{l}\text { Reliability } \\
\text { parameter }\end{array}$ & $\begin{array}{l}\text { Replenish } \\
\text { quantity }\end{array}$ & $\begin{array}{l}\text { Retailer's } \\
\text { profit }\end{array}$ & $\begin{array}{l}\text { Manufacturer's } \\
\text { profit }\end{array}$ & $\begin{array}{l}\text { Integrated } \\
\text { profit }\end{array}$ \\
$r^{*}$ & cost & $r^{*}$ & 6 & $Q$ & APR $^{*}$ & APM $^{*}$ & AIP* $^{*}$ \\
\hline 20 & 110.08 & 6 & 6 & 0.4930 & 25 & 2933.55 & 15772.86 & 18706.41 \\
30 & 97.16 & 6 & 7 & 0.1946 & 21.42 & 2937.76 & 15764.16 & 18701.92 \\
600 & 305.34 & 5 & 6 & 0.131 & 25 & 2933.55 & 15557.45 & 18491.00 \\
\hline
\end{tabular}

TABLE 8. Sensitivity analysis with respect to development cost parameter $B$ when $k=0.1$.

\begin{tabular}{lllllllll}
\hline \hline $\begin{array}{l}\text { Development } \\
\text { cost } \\
\text { parameter } B\end{array}$ & $\begin{array}{l}\text { Total } \\
\text { development }\end{array}$ & $\begin{array}{l}\text { Production } \\
\text { cycle }\end{array}$ & $\begin{array}{l}\text { Replenishment } \\
\text { cycle }\end{array}$ & $\begin{array}{l}\text { Reliability } \\
\text { parameter }\end{array}$ & $\begin{array}{l}\text { Replenish } \\
\text { quantity }\end{array}$ & $\begin{array}{l}\text { Retailer's } \\
\text { profit }\end{array}$ & $\begin{array}{l}\text { Manufacturer's } \\
\text { profit }\end{array}$ & $\begin{array}{l}\text { Integrated } \\
\text { profit } \\
\text { APR }\end{array}$ \\
\hline 600 & 396.26 & 14 & 15 & 0.3693 & 10 & 2946.42 & 15466.73 & 18413.15 \\
800 & 490.23 & 10 & 15 & 0.3180 & 13.64 & 2945.12 & 15367.83 & 18312.95 \\
\hline
\end{tabular}

higher than that for the case of higher production rate as the customer's demand $D_{c}$ and business period $n T$ are fixed.

\section{Sensitivity analysis 3}

It is seen from Tables 7 and 8 that as $B$ increases total development cost increases whereas the reliability parameter $\theta$ as well as average integrated profit (AIP) decreases. Again, the reliability $e^{-\theta t}$ of the manufacturing system is inversely proportional to the reliability parameter $\theta$. So, the reliability of the production system should be increased by increasing development cost upto a certain level for which the average integrated profit is optimum.

\section{Managerial Insight}

Based on the results obtained from Tables 3 to 8, Lemmas, and from Figures the following managerial insights are observed.

- It has been observed from the above discussion that the reliability of the production system can be maintain upto optimum level by regulating the development cost. Moreover, from Table 7 it is clear that, if production rate is increased, the system becomes less reliable. So, the production system can be made more reliable by incorporating development cost.

- Lemma 3.2 shows that the feasible region of the advance payment part $\alpha$ lies between 0 and $\frac{1}{3}$ and from Table 5 it is observed that within this range, retailer's average profit increases and whereas both manufacturer's average profit as well as average integrated profit decreases as $\alpha$ increases. As, in an integrated system, the manufacturer is the decision maker, he/she may urge the retailer to prepay a specified part of the purchasing cost of the replenishment quantity prior to delivery the order so that in perspective of profitability both are benefitted.

- Average integrated profit (AIP) can be increased by increasing minimum replenishment quantity $Q_{0}$ by motivating retailer subject to free transportation cost.

- When production rate $p$ increases, both average manufacturer's profit (APM) and average integrated profit (AIP) decreases. It is reasonable that when the production rate increases the system reliability parameter $\theta$ increases that is, the reliability of the production system decreases and consequently the system produces more defective items. In this model, both production rate $p$ and demand rate $D_{c}$ are considered as constant, so 
time dependent development cost is responsible to maintain reliability of the production system throughout the production length.

- When customer's demand $D_{c}$ increases, system reliability parameter $\theta$ decreases (i.e., the system reliability increases). So, to satisfy the customer's demand, the production system can be made more reliable by regulating development cost.

- When the advance payment part $\alpha$ increases within the feasible range $\left(0<\alpha<\frac{1}{3}\right)$, retailer's average profit (APR) increases. So the retailer must be much interested in advance payment (AP) scheme and hence secures demand for manufacturer.

- The relative profitability for the retailer discussed in numerical Examples is sufficient to motivate the retailer to pay in advance and hence to secure manufacturer's demand.

\section{Conclusions And Future Research}

In this model, a realistic integrated imperfect production-inventory model with two-layer supply chain has been developed. To confirm the order, the manufacturer motivates the retailer to pay a part of the purchasing cost of the replenishment quantity prior to delivary the items and invites to enjoy the benefits such as (i) delay in payment and (ii) free transportation on advance payment quantity. So many research papers relating to permissible delay in payments and also in advance payment have been published in different journals. But, till now none has considered an imperfect production-inventory model with two-layer supply chain incorporating partial advance and partial delay in payment for the retailer along with free transportation on advance payment quantity. Finally, the numerical illustrations with sensitivity analysis have been presented to study the feasibility of the proposed model. So, from this study the following conclusions have been made:

(i) This model has good impact to ensure the order for manufacturer by stimulating the retailer in partial advance and partial delay in payment scheme.

(ii) Solution Methodology for the proposed model has been developed and it provides optimal number of production cycle, number of replenishment cycle and hence replenishment cycle time, replenishment quantity, system reliability parameter that maximize average integrated profit.

One limitation of this paper is that the advance payment part $\alpha$ belongs to the range $0<\alpha<\frac{1}{3}$ as obtained in Lemma 3.2.

Some possible future directions for research are that: (i) the paper can be extended to imperfect production inventory model with two-layer supply chain with multi-items with fuzzy monsoon demand De and Mahata [12] and (ii) can be extended to imperfect production inventory model with three-layer supply chain retailer offers credit period to his/her customer.

Acknowledgements. The authors express their sincere thanks to the editor and the anonymous reviewers for their valuable and constructive comments and suggestions which have led to a significant improvement of the manuscript.

\section{REFERENCES}

[1] V. Agarwal, X. Chao and S. Seshadri, Dynamic balancing of inventory in supply chains. Eur. J. Oper. Res. 159 (2004) $296-317$.

[2] A. Banerjee, A joint echonomic lot-size-model for purchaser and vendor. Decis. Sci. 17 (2007) 292-311.

[3] A. Banu and S.K. Mondal, Analysis of credit linked demand in an inventory model with varying ordering cost. SpringerPlus. 5 (2016) 926.

[4] M. Ben-Daya and M. Hariga, Economic lot scheduling problem with imperfect production processes. J. Oper. Res. Soc. 51 (2000) 875-881.

[5] G.P. Cachon and P.H. Zipkin, Competitive and cooperative inventory policies in a two-stage supply chain. Manage. Sci. 45 (1999) 936-953.

[6] B.C. Das, B. Das and S.K. Mondal, An integrated supply chain for a deteriorating item with procurement cost dependent credit period. Comput. Ind. Eng. 64 (2013) 788-796.

[7] B.C. Das, B. Das and S.K. Mondal, An integrated production inventory model under interactive fuzzy credit period for deteriorating item with several markets. Appl. Soft Comput. 28 (2015) 453-465. 
[8] B.C. Das, B. Das and S.K. Mondal, An integrated production-inventory model with defective item dependent stochastic credit period. Comput. Ind. Eng. 110 (2017) 255-263.

[9] S.K. De and G.C. Mahata, A production inventory supply chain model with partial backordering and disruption under triangular linguistic dense fuzzy lock set approach. Soft Comput. 24 (2020) 5053-5069.

[10] S.K. De and G.C. Mahata, An EPQ model for three-layer supply chain with partial backordering and disruption: triangular dense fuzzy lock set approach. Sadhana 44 (2019) 177.

[11] S.K. De and G.C. Mahata, A cloudy fuzzy economic order quantity model for imperfect-quality items with allowable proportionate discounts. J. Ind. Eng. Int. 15 (2019) 571-583.

[12] S.K. De and G.C. Mahata, A comprehensive study of an economic order quantity model under fuzzy monsoon demand. Sadhana, Indian Acad. Sci. 44 (2019) 89.

[13] S.K. De and S.S. Sana, Two-layer supply chain model for cauchy type stochastic demand under fuzzy environment. Int. J. Intell. Comput. Cybern. 11 (2018) 285-308.

[14] S.K. Goyal, Economic order quantity under conditions of permissible delay in payments. J. Oper. Res. Soc. 36 (1985) $335-338$.

[15] S.K. Goyal, A joint echonomic-lot-size model for purchaser and vendor: a comment. Decis. Sci. 19 (1988) $236-241$.

[16] R.K. Gupta, A.K. Bhunia and S.K. Goyal, An application of Genetic Algorithm in solving an inventory model with advance payment and interval valued inventory costs. Math. Comput. Modell. 49 (2009) 893-905.

[17] M.A. Khan, A.A. Shaikh, G.C. Panda and I. Konstantaras, Two-warehouse inventory model for deteriorating items with partial backlogging and advance payment scheme. RAIRO:OR 53 (2019) 1691-1708.

[18] M.A. Khan, A.A. Shaikh, G.C. Panda, I. Konstantaras and L.E. Cardenas-Barron, The effect of advance payment with discount facility on supply decisions of deteriorating products whose demand is both price and stock dependent. Int. Trans. Oper. Res. 27 (2020) 1343-1367.

[19] B. Khara, J.K. Dey and S.K. Mondal, An inventory model under development cost dependent imperfect production and reliability dependent demand. J. Manage. Anal. 4 (2017) 258-275.

[20] B. Khara, J.K. Dey and S.K. Mondal, Sustainable recycling in an imperfect production system with acceptance quality level dependent development cost and demand. Comput. Ind. Eng. 142 (2020) 106300.

[21] B. Khara, J.K. Dey and S.K. Mondal, An integrated imperfect production system with advertisement dependent demand using branch and bound technique. To appear in: Flexible Serv. Manuf. J. (2020). DOI: 10.1007/s10696-020-09377-5.

[22] M. Khouja and A. Mehrez, An economic production lot size model with imperfect quality and variable production rate. J. Oper. Res. Soc. 45 (1994) 1405-1417.

[23] M. Lashgari, A.A. Taleizadeh and A. Ahmadi, Partial up-stream advanced payment and partial down-stream delayed payment in a three-level supply chain. Ann. Oper. Res. 238 (2016) 329-354.

[24] M. Lashgari, A.A. Taleizadeh and S.J. Sadjadi, Ordering policies for non-instantaneous deteriorating items under hybrid partial prepayment, partial trade credit and partial backordering. J. Oper. Res. Soc. 69 (2018) 1167-1196.

[25] R. Li, Y.L. Chan, C.T. Chang and L.E. Cárdenas-Barron, Pricing and lot-sizing policies for perishable products with advancecash-credit payments by a discounted cash-flow analysis. Int. J. Prod. Econ. 193 (2017) 578-589.

[26] Y. Liang and F. Zhou, A two-warehouse inventory model for deteriorating items under conditionally permissible delay in payment. Appl. Math. Modell. 35 (2011) 2221-2231.

[27] S. Ma, J. Lin, W. Xing and X. Zhao, Advance booking discount in the presence of spot market. Int. J. Prod. Res. 53 (2015) 2921-2936.

[28] S. Maity, A. Chakraborty, S.K. De, S.P. Mondal and S. Alam, A comprehensive study of a backlogging EOQ model with nonlinear heptagonal dense fuzzy environment. RAIRO:OR 54 (2020) 267-286.

[29] A.K. Manna, J.K. Dey and S.K. Mondal, Three-layer supply chain in an imperfect production inventory model with two storage facilities under fuzzy rough environment. J. Uncertainty Anal. App. 2 (2014) 17.

[30] A.K. Manna, B. Das, J.K. Dey and S.K. Mondal, Multi-item EPQ model with learning effect on imperfect production over fuzzy-random planning horizon. J. Manage. Anal. 4 (2016) 80-110.

[31] A.K. Manna, J.K. Dey and S.K. Mondal, Imperfect production inventory model with production rate dependent defective rate and advertisement dependent demand. Comput. Ind. Eng. 104 (2017) 9-22.

[32] M.J. Rosenblatt and H.L. Lee, Economic production cycles with imperfect production processes. IIE Trans. 18 (1986) $48-55$.

[33] M. Salameh and M.Y. Jaber, Economic production quantity model for items with imperfect quality. Int. J. Prod. Econ. 64 (2000) 59-64.

[34] S.S. Sana, A production-inventory model of imperfect quality products in a three-layer supply chain. Decis. Support Syst. 50 (2011) 539-547.

[35] A.A. Shaikh, S.C. Das, A.K. Bhunia, G.C. Panda and M.A. Khan, A two-warehouse EOQ model with interval-valued inventory cost and advance payment for deteriorating item under particle swarm optimization. Soft Comput. 23 (2019) 13531-13546.

[36] Y. Shi, Z. Zhang, S.C. Chen, L.E. Cardenas-Barron and K. Skouri, Optimal replenishment decisions for perishable products under cash, advance, and credit payments considering carbon tax regulations. Int. J. Prod. Econ. 223 (2020) 107514.

[37] A.A. Taleizadeh, An EOQ model with partial backordering and advance payments for an evaporating item. Int. J. Prod. Econ. 155 (2014) 185-193.

[38] A.A. Taleizadeh, Lot-sizing model with advance payment pricing and disruption in supply under planned partial backordering. Int. Trans. Oper. Res. 24 (2017) 783-800.

[39] A.A. Taleizadeh, D.W. Pentico, M.S. Jabalameli and M. Aryanezhad, An economic order quantity model with multiple partial prepayments and partial backordering. Math. Comput. Modell. 57 (2013) 311-323. 
[40] S. Tavakoli and A.A. Taleizadeh, An EOQ model for decaying item with full advanced payment and conditional discount. Ann. Oper. Res. 259 (2017) 415-436.

[41] A. Thangam, Optimal price discounting and lot-sizing policies for perishable items in a supply chain under advance payment scheme and two-echelon trade credits. Int. J. Prod. Econ. 139 (2012) 459-472.

[42] Q.H. Zhang, Y.C. Tsao and T.H. Chen, Economic order quantity under advance payment. Appl. Math. Modell. 38 (2014) 5910-5921.

[43] Q. Zhang, D. Zhang, Y.C. Tsao and J. Luo, Optimal ordering policy in a two-stage supply chain with advance payment for stable supply capacity. Int. J. Prod. Econ. 177 (2016) 34-43.

[44] N.P. Zia and A.A. Taleizadeh, A lot-sizing model with backordering under hybrid linked-to-order multiple advance payments and delayed payment. Transp. Res. Part E $\mathbf{8 2}$ (2015) 19-37. 